\title{
Non-deletional CD8+ $T$ cell self-tolerance permits responsiveness but limits tissue damage
}

Emily Nestor Truckenbrod ${ }^{1}$, Kristina S Burrack ${ }^{1,2}$, Todd P Knutson ${ }^{3}$, Henrique Borges da Silva ${ }^{1,4}$, Katharine E Block ${ }^{1}$, Katie R Stagliano ${ }^{5}$, Arthur A Hurwitz ${ }^{6}$, Ross B Fulton ${ }^{1,7}$, 6 Kristin R Renkema ${ }^{1,8^{*}}$, Stephen C Jameson ${ }^{1^{*}}$

${ }^{1}$ Center for Immunology, University of Minnesota; ${ }^{2}$ Current address: Hennepin

9 Healthcare Research Institute; ${ }^{3}$ Minnesota Supercomputing Institute, University of

10 Minnesota; ${ }^{4}$ Current address: Mayo Clinic Arizona; ${ }^{5} \mathrm{NIAID}, \mathrm{NIH}$;

$11{ }^{6}$ AgenTus Therapeutics, Inc.; ${ }^{7}$ Current address: iFiBiO Therapeutics, ${ }^{8}$ Current address:

12 Grand Valley State University

${ }^{*}$ Corresponding authors

Stephen Jameson: james024@umn.edu, ORCID: 0000-0001-9137-1146 


\section{Abstract}

23 Self-specific CD8+ T cells often escape clonal deletion, but the properties and capabilities of such cells in a physiological setting are unclear. We characterized polyclonal $\mathrm{CD}^{+} \mathrm{T}$ cells specific for the melanocyte antigen tyrosinase-related protein 2 (Trp2) in mice that express or lack this enzyme due to deficiency in Dct, which encodes Trp2. The size, phenotype, and gene expression profile of the pre-immune $\operatorname{Trp} 2 / \mathrm{K}^{\mathrm{b}}$ specific pool were similar in wild-type (WT) and $D c t$-deficient $\left(D c t^{--}\right)$mice. Despite comparable initial responses to Trp2 immunization, WT Trp2/ $\mathrm{K}^{\mathrm{b}}$-specific cells showed blunted expansion, and scRNAseq revealed WT cells less readily differentiated into a CD25+ proliferative population. Functional self-tolerance clearly emerged when assessing immunopathology: adoptively transferred WT $T r p 2 / \mathrm{K}^{\mathrm{b}}$-specific cells mediated vitiligo much less efficiently. Hence, $\mathrm{CD} 8^{+} \mathrm{T}$ cell self-specificity is poorly predicted by precursor frequency, phenotype or even initial responsiveness, while deficient activation-induced CD25 expression and other gene expression characteristics may help to identify functionally tolerant cells. 


\section{Introduction}

Accurate discrimination between harmful (pathogens, toxins, cancerous cells) and nonharmful entities (self, innocuous environmental components, non-pathogenic microbes) underlies effective functioning of the immune system. Understanding the mechanisms that normally enforce immunological tolerance to self is a prerequisite for safely and effectively manipulating the immune system to therapeutically induce or break selftolerance.

Tolerance can be mediated by the clonal deletion of developing self-reactive $\mathrm{T}$ cells (Hogquist et al., 2005; Kappler et al., 1987). Largely based on studies in transgenic mouse models, this process has long been regarded as common and highly efficient (Palmer, 2003). However, recent studies have revealed that thymic clonal deletion is less effective than previously thought (Richards et al., 2016). Self-reactive CD8+ T cells have been shown to escape negative selection in mice (Bouneaud et al., 2000; Zehn \& Bevan, 2006), with one group proposing that up to $4 \%$ of peripheral CD $8+$ T cells are self-specific (Richards et al., 2015). Furthermore, studies in humans indicated that precursor frequencies of blood CD8+ T cells specific for certain self-peptides were comparable to those demonstrated for foreign peptides (Yu et al., 2015) and suggested that such cells might be capable of overt autoreactivity if suitably stimulated (Maeda et al., 2014).

Aside from clonal deletion, tolerance mechanisms include ignorance of antigen, suppression by regulatory $T$ cells (Tregs), and induction of a functionally unresponsive or hyporesponsive anergic state (Mescher et al., 2007; Mueller, 2010; Redmond \& Sherman, 2005; Schietinger \& Greenberg, 2014). However, different models have produced conflicting evidence regarding the contribution of each of these mechanisms and whether non-deletional $\mathrm{CD}^{+} \mathrm{T}$ cell tolerance is an intrinsic property of tolerant cells (Yu et al., 2015) or dependent on restraint by Tregs (Maeda et al., 2014; Richards et al., 2015). It is also unclear how the presence and reactivity of self-specific CD8 ${ }^{+} \mathrm{T}$ cells relates to their ability to drive immunopathology. The majority of commonly-used mouse models of tolerance have the drawbacks of relying on T cell receptor (TCR) transgenic animals that may not recapitulate normal physiology or utilizing in vitro analyses for characterization of functionality.

Our studies are intended to provide a better understanding of non-deletional CD8+ T cell tolerance by utilizing a more physiologic and translationally-relevant mouse model in which an epitope from the melanocyte differentiation enzyme tyrosinase-related protein 2 (Trp2) is recognized by CD8+ T cells as either self or foreign. Tyrosinaserelated protein 2, an enzyme involved in melanin biosynthesis encoded by the dopachrome tautomerase $(D c t)$ gene, is normally expressed by melanocytes in the skin in both humans and C57BL/6 mice and is overexpressed by many melanomas (Avogadri et al., 2016; Wang et al., 1996). Using wild-type (WT) mice and a novel Dctdeficient $\left(D c t^{-}\right)$strain, we compared responses to $\operatorname{Trp} 2180-188 / \mathrm{K}^{\mathrm{b}}\left(\operatorname{Trp} 2 / \mathrm{K}^{\mathrm{b}}\right)$ as a self84 versus foreign antigen. This model is relevant to human health, as Trp2 is a common 
85 target in cancer immunotherapy directed against melanoma (Cho \& Celis, 2009; Liu et al., 2014; Parkhurst et al., 1998), and Trp2/Kb-specific responses can be induced in WT mice with vigorous priming approaches (Bowne et al., 1999; Byrne et al., 2011; Cho \& Celis, 2009). Instead of utilizing TCR transgenic models, we focus on the polyclonal Trp2/Kb-specific CD8+ T cell repertoire to maximize applicability to normal physiology.

Here, we show that tolerance among $\operatorname{Trp} 2 / \mathrm{K}^{\mathrm{b}}$-specific $\mathrm{CD} 8^{+} \mathrm{T}$ cells is manifest primarily at the level of minimizing overt autoimmunity, with few differences in the size, phenotype, and initial Trp2 responsiveness of the precursor pool in WT and $D c t^{\prime-}$ mice. The underlying tolerance mechanism does not depend on cell-extrinsic regulation but rather correlates with a cell-intrinsic failure of WT Trp2/K $\mathrm{K}^{\mathrm{b}}$-specific CD8 ${ }^{+} \mathrm{T}$ cells to sustain optimal proliferation. However, while differences in the responsiveness of WT and $D c t^{\prime-}$ cells to Trp2 immunization were mostly subtle, a notable difference emerged when the cells were assessed for their ability to provoke autoimmune vitiligo: cells primed in $\mathrm{Dct}^{--}$mice were much more effective than those primed in WT animals. Accordingly, we conclude that tolerance does not markedly impact the presence, phenotype, or initial reactivity of $\operatorname{Trp} 2 / \mathrm{K}^{\mathrm{b}}$-specific $\mathrm{CD} 8^{+} \mathrm{T}$ cells but severely limits whether these cells are capable of overt autoreactivity. Moreover, our polyclonal model reveals that certain characteristics of Trp2/K $\mathrm{K}^{\mathrm{b}}$-responsive effector cells - reduced CD25 expression and impaired differentiation into a highly proliferative subpopulation correlate with functional tolerance of a T cell population, providing a framework for future characterization of self-specific $C D 8^{+} \mathrm{T}$ cells. 


\section{Results}

The pre-immune population of Trp $2 / K^{b}$-specific cells is similarly sized and appears naïve in WT and Dct'- mice

Clonal deletion is a well-studied tolerance mechanism that may result in the near-total culling of self-specific cells or at least a marked reduction and reduced apparent TCR affinity of surviving self-specific cells (Bouneaud et al., 2000; Cheng \& Anderson, 2018; Enouz et al., 2012; Hogquist et al., 2005; Zehn \& Bevan, 2006). We assessed the number and phenotype of Trp2/K $\mathrm{K}$-specific cells in pre-immune (naïve) mice to examine deletional central tolerance in our model. For mice in which Trp2 would not be a selfantigen, we used a novel $\mathrm{Dct}^{- \text {- }}$ strain that carries a large deletion encompassing the exon encoding Trp2180-188, unlike a previously described Dct-targeted strain that retains the coding sequence for that epitope (Guyonneau et al., 2004). We performed tetramer enrichment from the spleen and lymph nodes of pre-immune WT and $D c t^{--}$mice to quantify the number of Trp2/K $/ \mathrm{K}^{\mathrm{b}}$-specific CD8+ T cell precursors (Figure $1 \mathrm{~A}, \mathrm{~S} 1 \mathrm{~A}$ ). While we identified slightly more antigen-specific cells in $D c t^{-1}$ mice, we nevertheless found relatively large numbers of $\operatorname{Trp} 2 / \mathrm{K}^{\mathrm{b}}$-specific CD8+ T cells $(>1500)$ in both strains, evidence that most $\mathrm{Trp} 2 / \mathrm{K}^{\mathrm{b}}$-specific cells escape thymic or peripheral clonal deletion in 128 WT mice.

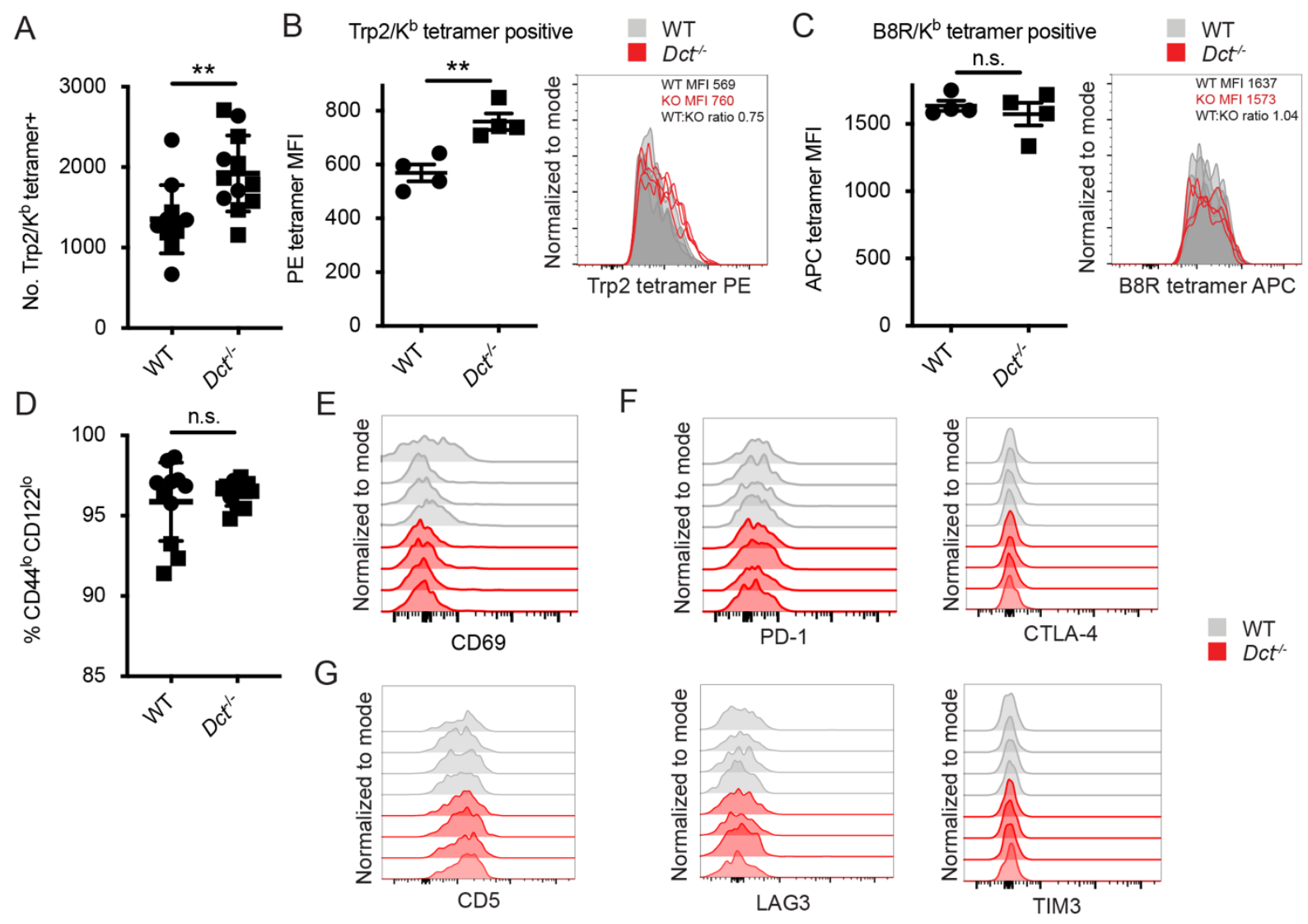


Figure 1. Trp2/Kb-specific CD8+ T cells in pre-immune WT and $\mathrm{Dct}^{/-}$mice share a naïve phenotype while showing modest differences in frequency and tetramer staining Tetramer enrichment was performed to enumerate Trp2/Kb-specific CD8+ T cells per mouse (A). Median tetramer fluorescence intensity (MFI) was used to estimate the avidity of enriched $\mathrm{Trp} 2 / \mathrm{K}^{\mathrm{b}}$ specific (B) or B8R/K $K^{\mathrm{b}}$-specific cells (C). (D) CD44/CD122 expression of Trp2/K $\mathrm{K}^{\mathrm{b}}$-specific cells. (E)

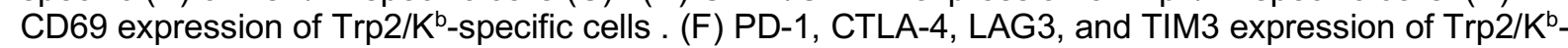
specific cells. (G) CD5 expression of Trp2/ $\mathrm{K}^{\mathrm{b}}$-specific cells. Data are compiled from three independent experiments in A and D. Four WT and $D c t^{/-}$mice are shown in B and C; results are representative of other experiments. The graphs in Figures $1 \mathrm{E}-\mathrm{G}$ represent individual experiments with four mice per group. Squares indicate male animals. ${ }^{* *} p<0.01$ by unpaired $t$ test.

In some systems, T cells bearing TCRs with low affinity for self-antigens avoid deletion; low affinity TCRs can often be identified by reduced peptide/MHC tetramer binding to these cells (Bouneaud et al., 2000; Daniels \& Jameson, 2000; Daniels et al., 2006; Enouz et al., 2012; Hogquist et al., 2005; Zehn \& Bevan, 2006; Zehn et al., 2009). We compared the Trp2/K $\mathrm{K}^{\mathrm{b}}$ tetramer median fluorescence intensity (MFI) in pre-immune WT and $\mathrm{Dct}^{--}$mice. The average $\operatorname{Trp} 2 / \mathrm{K}^{\mathrm{b}}$ tetramer staining was higher on $D c t^{--}$cells, but the MFI largely overlapped between the two populations (Figure 1B), suggesting that the range of TCR avidities did not markedly differ between the Trp2/K $\mathrm{K}^{\mathrm{b}}$-specific pools. Indeed, the tetramer staining differences we observed (a WT:Dct/- tetramer MFI ratio of $\sim 0.75$ ) are more subtle than that noted in a previous study using a transgenic mouse model, which reported a tetramer ratio of $\sim 0.35$ between mice with vs. without selfantigen expression (Bouneaud et al., 2000). As a control, we also assessed the avidity of cells specific for an irrelevant foreign epitope-B8R/K ${ }^{\text {b }}$ from vaccinia virus-in WT and $D c t^{--}$mice; the tetramer MFI of $\mathrm{B} 8 \mathrm{R} / \mathrm{K}^{\mathrm{b}}$-specific cells was comparable between the strains (Figure 1C).

We also examined the phenotype of Trp2/K mice. No consistent differences in the expression of activation/memory markers (CD69, CD44, CD122) or anergy/exhaustion markers (PD-1, LAG3, CTLA-4, TIM3) were identified between $\mathrm{Dct}^{--}$and WT Trp2/K $\mathrm{K}^{\mathrm{b}}$-specific cells (Figures $1 \mathrm{C}-\mathrm{F}, \mathrm{S} 1 \mathrm{~B}, \mathrm{~S} 1 \mathrm{C}$ ). The majority of cells exhibited low expression of the memory markers CD44 and CD122, and anergy/exhaustion marker expression was low in both populations. CD5 can indicate self-antigen recognition (Azzam et al., 1998; Fulton et al., 2015), but we did not detect significant differences in expression between the groups (Figure 1G). RNAseq analysis of $\operatorname{Trp} 2 / \mathrm{K}^{\mathrm{b}}$ tetramer-binding cells isolated from pre-immune mice by fluorescence-activated cell sorting (FACS) showed no consistent differences in gene expression related to their derivation from WT versus $D c t^{--}$mice (Supplemental figure 1D), although this does not rule out the possibility of epigenetic differences between the populations.

To ensure our findings were not unique to $\operatorname{Trp} 2_{180} / \mathrm{K}^{\mathrm{b}}$-specific cells, we used tetramer enrichment to isolate CD8+ T cells specific for other skin antigens-a distinct Trp2 epitope $\left(\operatorname{Trp} 2_{363} / D^{b}\right)$ and a tyrosinase-related protein 1 epitope $\left(\operatorname{Trp} 1_{455} / D^{b}\right)$-in mice expressing or lacking these antigens. We were able to identify cells with these specificities present at numbers similar to slightly less in mice expressing antigen 
relative to mutant mice (Supplemental figure 1E). This suggests that CD8+ T cells specific for other melanocyte self-epitopes also largely escape clonal deletion.

Hence, although we identified some minor differences between $\operatorname{Trp} 2 / \mathrm{K}^{\mathrm{b}}$-specific cells from WT versus $\mathrm{Dct}^{--}$mice, these pre-immune populations generally resembled each other in number, phenotype, and gene expression, arguing against a major role for clonal deletion or overt steady-state anergy induction as tolerance mechanisms to this antigen. These findings resonate with studies in humans, which have shown that the precursor frequency and peptide/MHC tetramer staining intensity were only modestly reduced for a self- versus non-self antigen (Yu et al., 2015) and that self-specific cells can be phenotypically naïve (Maeda et al., 2014; Yu et al., 2015). Accordingly, these data suggested that analysis of the $\operatorname{Trp} 2 / \mathrm{K}^{\mathrm{b}}$-specific responses in mice could serve as a useful model to investigate the basis for and limits of non-deletional self-tolerance.

\section{WT Trp2/K $K^{b}$-specific CD8+ T cells display impaired responses to Trp2 immunization}

It was possible that the lack of substantial clonal deletion or signs of prior activation in WT Trp2/Kb-specific cells indicated "ignorance" of Trp2 and/or that the Trp2 180 epitope, which shows suboptimal binding to $\mathrm{K}^{\mathrm{b}}$ (McWilliams et al., 2006), was unable to prime a vigorous immune response. To investigate this, we challenged WT and $D c t^{--}$mice with Trp2 in an immunogenic context using TriVax, a subunit immunization strategy comprising peptide, agonist anti-CD40 antibody, and poly(I:C) (Cho \& Celis, 2009). It should be noted that the TriVax approach uses the minimal peptide for priming, which likely excludes antigen-specific Treg involvement. We included B8R peptide in addition to Trp2 peptide in these experiments as an internal control. While WT and $D c t^{-1}$ mice responded similarly to B8R, WT mice showed a more limited response to Trp2 at an effector time point (day 7 ) relative to $D c t^{--}$mice (Figure $2 \mathrm{~A}, \mathrm{~B}$ ), ruling out ignorance as the dominant tolerance mechanism. We observed a significantly larger number and frequency of Trp2/K $/ \mathrm{K}^{\mathrm{b}}$-specific cells in $D c t^{\prime-}$ mice, and the $D c t^{\prime-}$ cells exhibited higher apparent Trp2/Kb avidity (as measured by tetramer MFI; Figure $2 \mathrm{C}-\mathrm{E}$ ). Still, WT Trp2/Kb-specific cells expanded $>1000$-fold $\left(D c t^{\prime-}\right.$ cells expanded $\sim 4000$-fold). The WT:Dct ${ }^{-1}$ tetramer ratio was little changed relative to the pre-immune populations, suggesting the difference in avidity between WT and $D c t^{--}$cells had not been amplified by activation. The frequency of PD-1+ cells was comparable between WT and Dct ${ }^{1-}$ Trp2/Kb-specific populations at this time point (Figure $2 \mathrm{~F}$ ), suggesting similar exposure to antigen.

To ensure that our results were not specific to the TriVax system, we also infected mice with a recombinant Listeria monocytogenes strain expressing Trp2 (LmTrp2) (Bruhn et al., 2005) and sacrificed the mice at effector (day 7) and memory (day 45) time points, assessing the percentage and number of Trp2/K $\mathrm{K}^{\mathrm{b}}$-specific CD8+ T cells and cytokine production in response to ex vivo Trp2 stimulation. Again, the Trp2/Kb-specific response was greater in $D c t^{--}$mice at both effector and memory time points (Supplemental figures 2A-C). Similarly, the frequency of all CD8+ T cells responding to ex vivo Trp2 stimulation with cytokine production (IFN- $\gamma$, TNF- $\alpha$ ) was larger in $D c t^{-1}$ mice; the percent producing IFN-y approximated the tetramer-positive population, suggesting that the 
212 majority of Trp2/Kb-specific cells were able to produce this cytokine in both strains of 213 mice (Supplemental figure 2D). Among IFN-y-producing cells, those from Dct $^{/-}$mice 214 tended to produce increased amounts of cytokine on a per-cell basis (as assessed by 215 IFN-Y MFI).

216

217
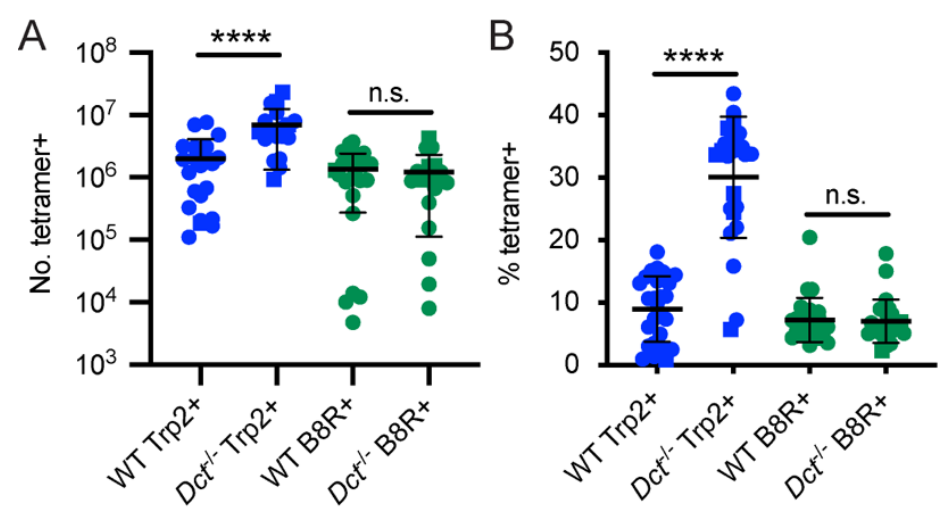

C $\quad \operatorname{Trp} 2 / \mathrm{K}^{\mathrm{b}}$ tetramer positive

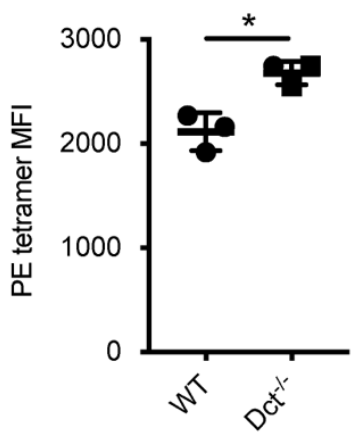

E

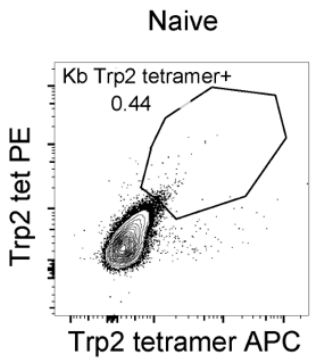

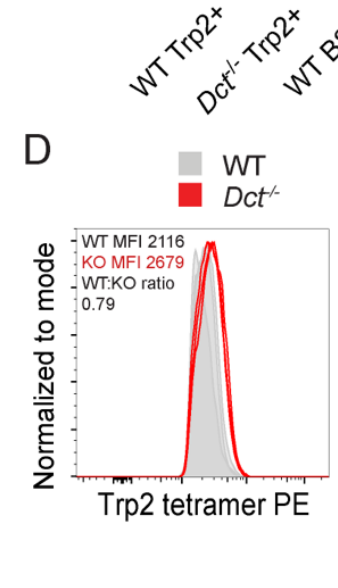

WT

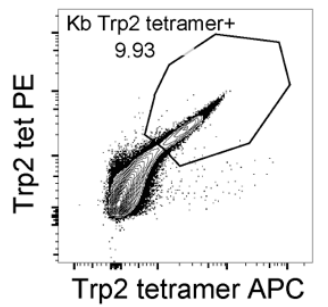

$\mathrm{F}$

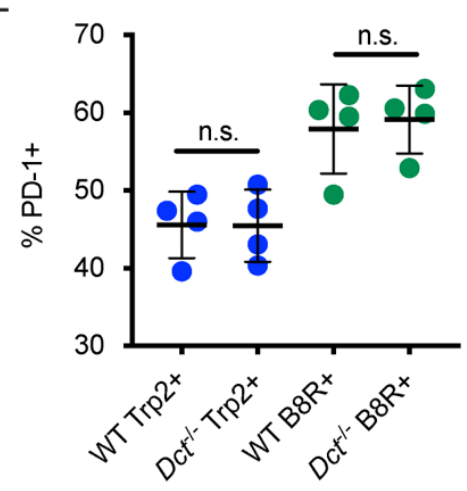

Dct ${ }^{-1}$

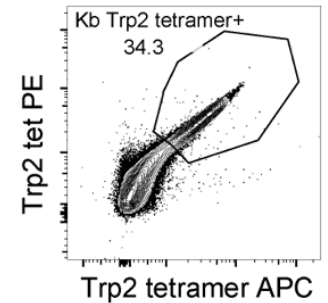

Figure 2. WT and $D c t^{-1-} \operatorname{Trp}^{2} / \mathrm{K}^{\mathrm{b}}$-specific cells respond differently to immunization with Trp2 Mice were primed with TriVax (50 ug each of Trp2 and B8R peptides; A-F). The number (A) or percent (B) of splenic Trp2/ $\mathrm{K}^{\mathrm{b}}$ or B8R/Kbecific cells was assessed at the day seven. (C, D) The tetramer

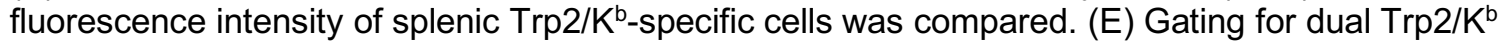
tetramer positive CD8+. (F) The frequency of the indicated splenic population expressing PD-1 is shown. Data in A and B are compiled from more than three experiments. Data in $C-F$ are representative of three or more similar experiments. Squares indicate male animals. ${ }^{*} p<0.05$, ${ }^{* * * *} p<0.0001$ by unpaired $t$ test $(C)$ or one-way ANOVA with Sidak's multiple comparisons test $(A, B, F)$.

\section{Tolerance to Trp2/Kb is $C D 8^{+} T$ cell-intrinsic}

Both cell-intrinsic and cell-extrinsic mechanisms of CD8+ T cell tolerance have been previously described. Sakaguchi's group (Maeda et al., 2014) identified anergic CD8+ T cells specific for melanocyte antigens in healthy human donors and concluded that 
these cells were restrained by Tregs. In contrast, other groups have shown cell-intrinsic deficits among self-reactive CD8+ T cells. For example, Davis' group (Yu et al., 2015) found human self-antigen-specific $T$ cells to be poorly responsive to antigenic stimulation even in the absence of Tregs, and Greenberg and colleagues (Schietinger et al., 2012) showed that tolerant self-reactive murine CD8+ T cells remained tolerant when transferred into new hosts that lacked antigen expression.

A

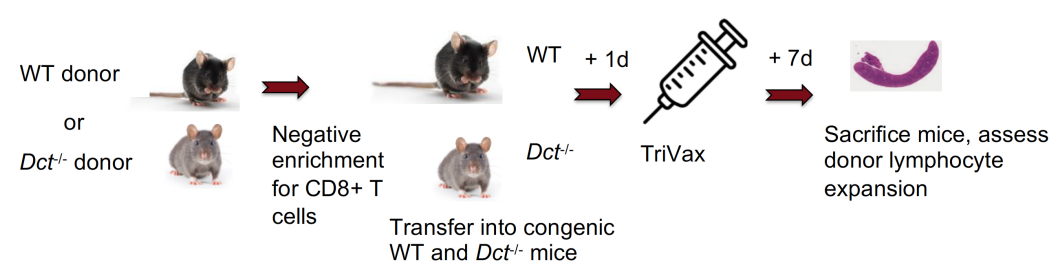

B

WT transfer

C

$D c t^{-1-}$ transfer

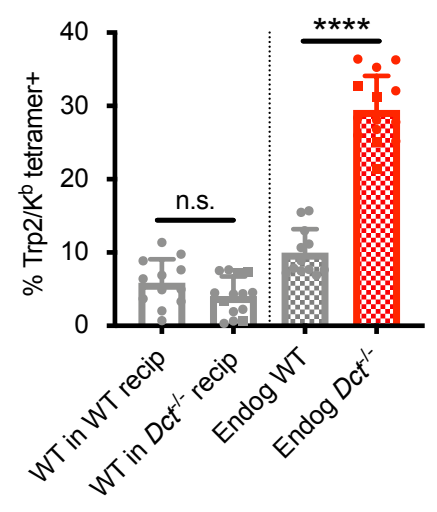

D WT transfer

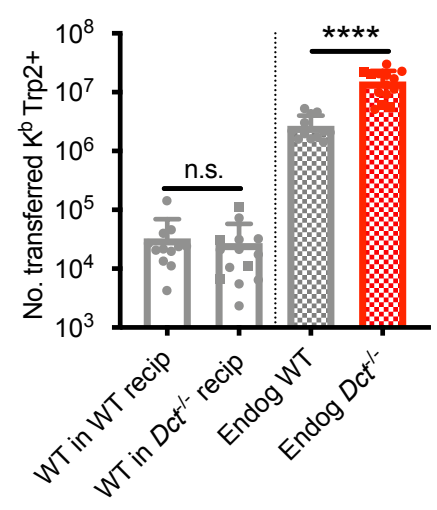

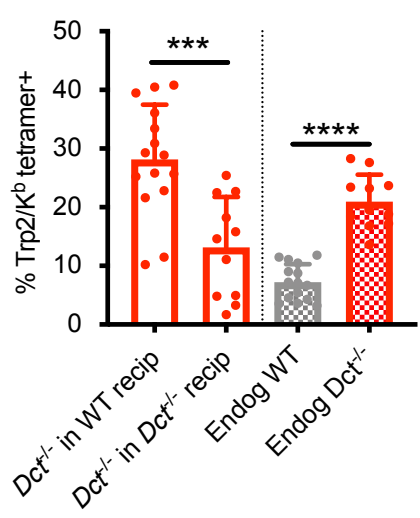

E

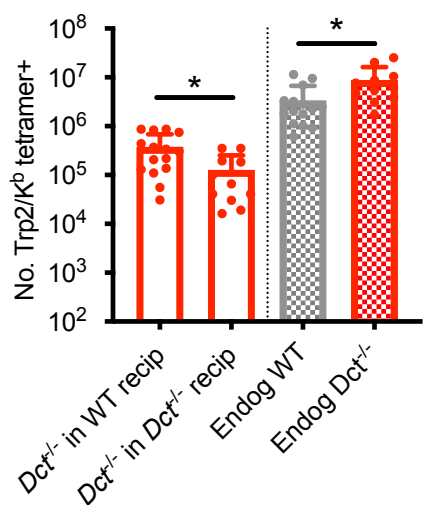

Figure 3. WT Trp2/Kb-specific cells exhibit cell-intrinsic tolerance

(A) We performed negative enrichment for CD8+ T cells from WT or Dct ${ }^{-1-}$ donors and transferred bulk CD8+ T cells into congenically distinct WT or $D c t^{-/}$recipients. One day later, mice were immunized with TriVax (100 ug of Trp2 and B8R peptide). Donor and endogenous cells were collected from the spleens of recipient mice on day seven following immunization and assessed for the percent $(B, C)$ and number $(D, E)$ of $\operatorname{Trp} 2 / \mathrm{K}^{\mathrm{b}}$ binding cells. Data in B-E were compiled from three or more experiments. Squares indicate male animals. ${ }^{*} p<0.05,{ }^{* * *} p<0.001,{ }^{* * * *} p<$ 0.0001 by one-way ANOVA with Sidak's multiple comparisons test. Endog, endogenous; recip, recipients.

Accordingly, we investigated whether cell-intrinsic or -extrinsic mechanisms were active in restraining Trp2 $/ \mathrm{K}^{\mathrm{b}}$-specific CD8+ T cells in WT mice. To assess this, we transferred bulk WT polyclonal CD8+ T cells to both WT and $D c t^{/-}$recipients, then primed the mice with TriVax and examined the effector response at day 7 post-immunization (Figure 3A, 3B, 3D). Transferred WT Trp2/ $\mathrm{K}^{\mathrm{b}}$-specific cells did proliferate ( 100 -fold expansion), albeit to a much lesser degree than endogenous $D c t^{-1-} \operatorname{Trp}^{2} / \mathrm{K}^{\mathrm{b}}$-specific cells. Importantly, their expansion was comparable in both WT and $D c t^{-/}$recipients (Figure 
3B, D), suggesting that the WT CD8 ${ }^{+} \mathrm{T}$ cells remained hyporesponsive even in an environment where endogenous cells were not tolerant to Trp2, supporting a cellintrinsic basis for the impaired reactivity of WT Trp2/ $/ \mathrm{K}^{\mathrm{b}}$-specific $\mathrm{CD} 8^{+} \mathrm{T}$ cells.

We also assessed the performance of $D c t^{--} \mathrm{CD}^{+} \mathrm{T}$ cells when transferred into $\mathrm{Dct}^{-}$ and WT hosts prior to priming to determine whether they would acquire tolerance in the WT environment (Figure 3A). These Trp2/ $\mathrm{K}^{\mathrm{b}}$-specific donor cells were able to expand robustly in both $D c t^{l-}$ and WT recipients (Figure $3 \mathrm{C}, \mathrm{E}$ ), further demonstrating a lack of extrinsic regulation in the WT environment. $D c t^{\prime-}$ cells actually performed better in WT recipients than in $\mathrm{Dct}^{/-}$recipients; the basis for this outcome is not clear but could be due to reduced competition by endogenous Trp $2 / \mathrm{K}^{\mathrm{b}}$-specific cells in WT hosts. Preliminary studies indicated that $D c t^{--}$cells still showed strong expansion when the interval between cell transfer and TriVax was extended from one day to one week, suggesting that these cells did not acquire tolerance characteristics within this timeframe (data not shown).

We conducted similar transfers utilizing LmTrp2 instead of TriVax, again finding evidence of cell-intrinsic tolerance. The transferred cells behaved in accordance with the donors' Trp2 expression rather than that of the recipients: WT cells remained tolerant when primed in $D c t^{/-}$recipients, while $D c t^{/-}$cells retained the ability to expand when primed in WT recipients (Supplemental figure 2E, 2F). Collectively, these data indicate that cell-intrinsic mechanism(s) enforce tolerance among WT Trp2/K $\mathrm{K}^{\mathrm{b}}$-specific cells.

\section{$\underline{W T}$ Trp2/Kb-specific cells are capable of an acute response to Trp2}

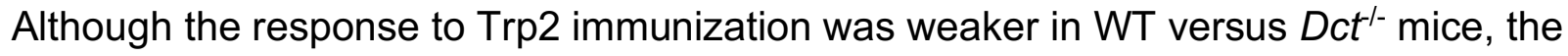
WT response was still substantial (Figure 2A). Studies on T cells with low affinity TCRs have shown a normal initial proliferative response that stalls prematurely relative to the response by high affinity T cells (Enouz et al., 2012; Ozga et al., 2016; Zehn et al., 2009). Alternatively, it was possible that fewer clones would be recruited into the Trp2 response in WT mice, leading to decreased expansion relative to $D c t^{/-}$animals from the initiation of an immune response. To distinguish between these possibilities, we studied

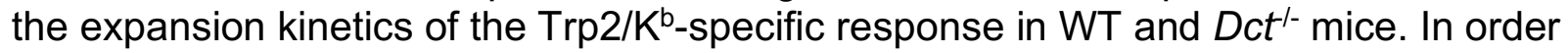
to track early polyclonal responses, TriVax with a higher dose of Trp2 peptide was used in these studies, and tetramer enrichment was used to isolate Trp2/ $\mathrm{K}^{\mathrm{b}}$-specific cells. Interestingly, WT Trp2/ $\mathrm{K}^{\mathrm{b}}$-specific cells were capable of an initial response that largely paralleled that shown by their $D c t^{-}$counterparts (Figure 4A). One day after TriVax immunization, few cells were isolated, likely due to either trapping within the tissues (Weninger et al., 2001) or TCR downregulation (Cai et al., 1997). Slightly more Trp2/K $\mathrm{K}^{\mathrm{b}}$ specific cells were identified in WT mice on day two, while increased numbers of Trp2/ $\mathrm{K}^{\mathrm{b}}$-specific cells were seen in $D c t^{--}$mice on days three through five. By days six and seven after high dose TriVax immunization, Trp2/ $/ \mathrm{K}^{\mathrm{b}}$-specific cells in $D c t^{/-}$mice outnumbered those in WT mice by an average ratio of $4: 1$. Although significant, these differences in expansion were modest in comparison with the $>1000$-fold expansion of Trp2/ $/ \mathrm{K}^{\mathrm{b}}$-specific cells in both strains (Figure $4 \mathrm{~A}$ ). Preliminary assessment of apoptosis 

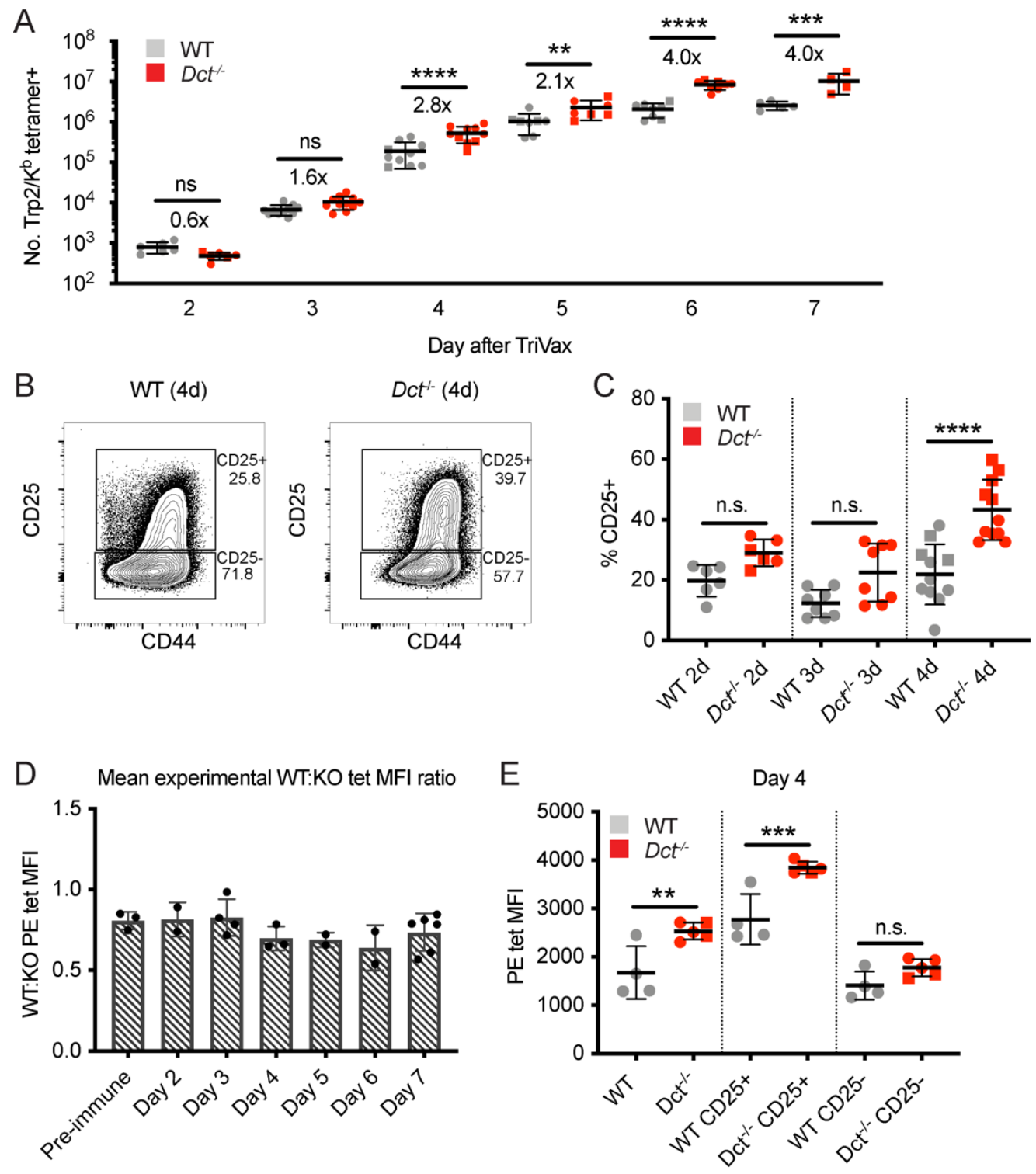

Figure 4. WT Trp2/K $\mathrm{K}^{\mathrm{b}}$-specific cells are capable of an initial response to $\operatorname{Trp2}$ similar to that of Dct ${ }^{--}$cells

WT and $D c t^{-}$mice received intravenous injections of TriVax with $200 \mathrm{ug}$ Trp2 peptide. Tetramer enrichment was used to enumerate Trp2/ $\mathrm{K}^{\mathrm{b}}$-specific cells and assess their phenotype at the indicated time points following immunization $(A-C, E)$. The ratio between the mean experimental $P E$ MFI of Trp2/ $\mathrm{K}^{\mathrm{b}}$-specific cells in WT mice relative to $D c t^{--}$mice is plotted in $\mathrm{D}$, with each symbol representing one experiment. Data are compiled from three or more experiments in A, D, and D. Representative flow plots from one day four experiment are shown in B, and the same representative day four experiment is shown in $\mathrm{E}$. Squares indicate male animals; the dotted line indicates the average naïve precursor frequency from the spleen and lymph nodes. ${ }^{*} p<0.05,{ }^{* *} p<0.01,{ }^{* * *} p<$ $0.001,{ }^{* * * *} p<0.0001$ by one-way ANOVA with Sidak's multiple comparisons test (performed on logtransformed data in [a]). 
We also assessed the phenotype of responding Trp $2 / \mathrm{K}^{\mathrm{b}}$-specific cells acutely after TriVax. With this approach, CD69 did not serve as a reliable indicator of activation due to the type I interferon response induced by poly(I:C) leading to CD69 upregulation (Shiow et al., 2006), and widespread CD44 expression was seen in both tetramer positive and negative cells because of the potent inflammatory response unleashed by this method of immunization. Accordingly, we tracked CD25 expression as an indicator of activation. CD25, the high affinity alpha component of the IL-2 receptor, is upregulated with activation in certain situations (Valenzuela et al., 2002) and may enable a stronger effector response by cells expressing it (Obar et al., 2010). The proportion of Trp2 $/ \mathrm{K}^{\mathrm{b}}$-specific cells expressing CD25 was significantly greater in $\mathrm{Dct}^{\prime-}$ mice on day four, and trended higher on days two and three (Figure 4B, 4C). The CD25 MFI of CD25+ cells was also higher on $D c t^{\prime-}$ Trp2/ $/ \mathrm{K}^{\mathrm{b}}$-specific cells on day four (Figure 4B), suggesting that $D c t^{-}$cells expressed more CD25 on a per-cell basis. Once again, Dct ${ }^{1-} \mathrm{Trp2} / \mathrm{K}^{\mathrm{b}}$-specific cells displayed significantly higher tetramer MFI than WT cells on days two through seven, but the avidity differences detected by tetramer staining did not demonstrate a progressive increase with time; the ratio between the WT and $D c t^{\prime-}$ tetramer MFI transiently dropped at days $4-6$, but the ratio at day 7 was similar to that of pre-immune cells (Figure 4D, S3A). Tetramer MFI was highest among the CD25+ subset for both WT and $D c t^{-}$cells; the tetramer MFI of CD25+ WT cells was similar to the MFI of the overall tetramer-binding $D c t^{--}$population on day four (Figure 4E).

We also assessed the early response following peptide stimulation alone, since this would be analogous to encountering Trp2 in a non-inflammatory context. We again found the early response to be similar between WT and $D c t^{-1} \mathrm{Trp} 2 / \mathrm{K}^{\mathrm{b}}$-specific cells. The number (Supplemental figure 3B) and phenotype of WT Trp2/K $\mathrm{K}^{\mathrm{b}}$-specific cells was comparable to that of $D c t^{/-}$cells on day one post-peptide. The activation markers CD44 and CD69 were similarly upregulated in both (Supplemental figure 3C, 3D), however, responses began to diverge by day two after peptide stimulation, and by day three significant differences in number and CD44 expression had emerged, with Dct/- cells clearly outperforming WT cells (Supplemental figure 3B, 3C).

These findings indicate that the response to $\operatorname{Trp} 2 / \mathrm{K}^{\mathrm{b}}$ in WT and $D c t^{--}$mice follows similar kinetics and magnitude but that expansion in WT animals terminates prematurely. Interestingly, we did not observe a progressive increase in apparent TCR avidity over time among the $D c t^{-}$responder pool relative to WT cells, as might be expected if the subset of $D c t^{-1} \mathrm{~T}$ cells with higher avidity TCRs became more dominant in the response to $\mathrm{Trp} 2 / \mathrm{K}^{\mathrm{b}}$.

\section{Single-cell sequencing reveals an impaired ability to differentiate into a highly} proliferative population among WT Trp $2 / K^{b}$-specific cells

To better understand the defects in expansion and functionality observed among WT $\operatorname{Trp} 2 / \mathrm{K}^{\mathrm{b}}$-specific cells and assess the heterogeneity within this population, we performed single-cell RNA sequencing on Trp2/K $\mathrm{K}^{\mathrm{b}}$-specific cells from WT and $D c t^{\prime-}$ mice at day

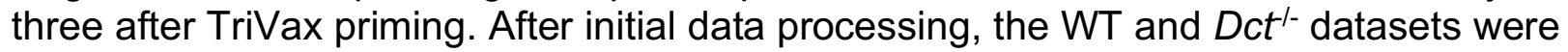
merged (Stuart et al., 2019); clusters based on the cells' transcriptomes were generated 
in an unbiased manner and visualized using uniform manifold approximation and projection (UMAP). Cells clustered into two major groups separated along the $x$-axis, each comprised of smaller clusters (Figure 5A). Interestingly, over half of the cells $(58 \%)$ from $D c t^{-1}$ mice were localized in cluster 0 , but this cluster was nearly devoid of WT cells, representing only a small subset (13\%) of WT cells (Figure 5B). Suspecting that this cluster might contain a more functional subset poorly represented in the WT population, we assessed its characteristics in more detail. Because this cluster made up the majority of Group A (left group), we performed differential gene expression analysis between the two major groups in the merged dataset: $A$ and $B$ (right group).

Histone genes (e.g., Hist1h1b, Hist1h1e, Hist1h1d, Hist2h2ac) were among the most upregulated in Group A compared to Group B; these genes are commonly induced in association with cellular replication (Mei et al., 2017). Other genes associated with proliferation, such as Myc, Nolc1, Npm1, and Ccne2, were also upregulated in Group A (Figure 5C), and cell cycle analysis revealed that the majority of cells in Group A were in stages G2/M or S of the cell cycle (Figure 5D). Among cells in cluster 0 (Group A), 76\% of $\mathrm{Dct}^{1-}$ cells were in G2/M or S versus $42 \%$ of WT cells (Figure $5 \mathrm{E}$ ). Gene set enrichment analysis revealed a strong enrichment of gene sets comprising Myc targets, E2F targets, and genes related to $\mathrm{mTORC} 1$ signaling and the G2/M checkpoint (Supplemental figure 4A).

Many of the cells in Group A expressed CD25, with the majority of the remainder located in cluster 2 of Group B (Figure 5F); cells in these clusters also showed enrichment for a gene signature associated with IL-2 receptor signaling (Supplemental figure 4B). This aligns with our finding that the frequency of cells expressing CD25 was greater in $\mathrm{Dct}^{--}$than WT Trp2/K $\mathrm{K}^{\mathrm{b}}$-specific effectors (Figure $4 \mathrm{C}$ ). Indeed, group A cells showed significantly higher expression of certain genes relevant to the IL-2 signaling pathway with known impacts on T cell function, such as Irf4 and Myc; previous work has demonstrated that signaling through the IL-2 receptor is important for sustained Myc expression (Preston et al., 2015). Based on these data, we administered IL-2 complex (IL-2 + anti-IL-2 S4B6 antibody) treatment to WT and Dct ${ }^{-}$mice previously primed with TriVax to determine whether this would correct the defective proliferation of the WT Trp2/K $\mathrm{K}^{\mathrm{b}}$-specific cells. IL-2 complex acts through the $\beta$ and $\gamma$ components of the IL-2 receptor, negating the impact of differential CD25 expression. IL-2 complex treatment on day five after TriVax or LmTrp2 improved the expansion of both WT and Dct ${ }^{--}$ $\operatorname{Trp} 2 / \mathrm{K}^{\mathrm{b}}$ specific cells to a similar extent (Supplemental figure 4C, 4D). Although this treatment did not correct the expansion defect of WT Trp2/K $\mathrm{K}^{\mathrm{b}}$-specific cells in a selective manner, it did improve their numbers to the level seen among untreated $\mathrm{Dct}^{\mathrm{I}}$ cells, supporting the use of IL-2R-directed therapies in cancer immunotherapy designed to engage tolerant cells (Moynihan et al., 2016; Rosenberg, 2014; Waithman et al., 2008). 
bioRxiv preprint doi: $\mathrm{https}$ //doi.org/10.1101/2020.12.16.423036; this version posted December 16, 2020. The copyright holder for this preprint (which was not certified by peer review) is the author/funder, who has granted bioRxiv a license to display the preprint in perpetuity. It is made available under aCC-BY 4.0 International license.
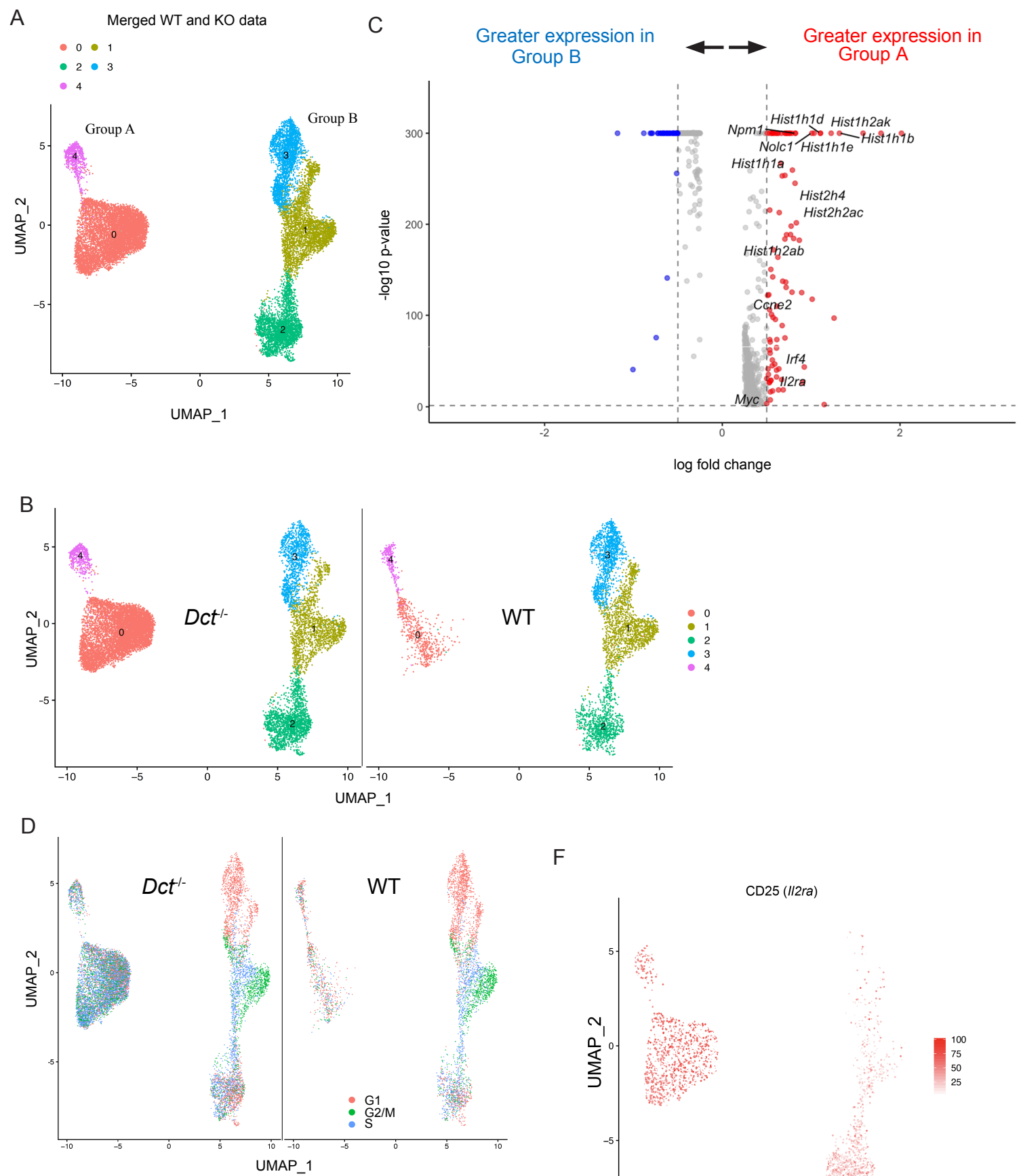

$\mathrm{E}$

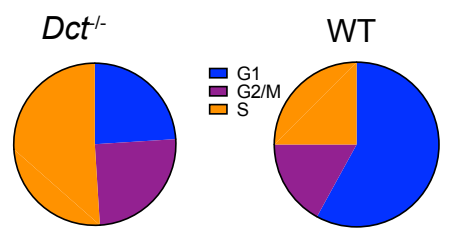

F

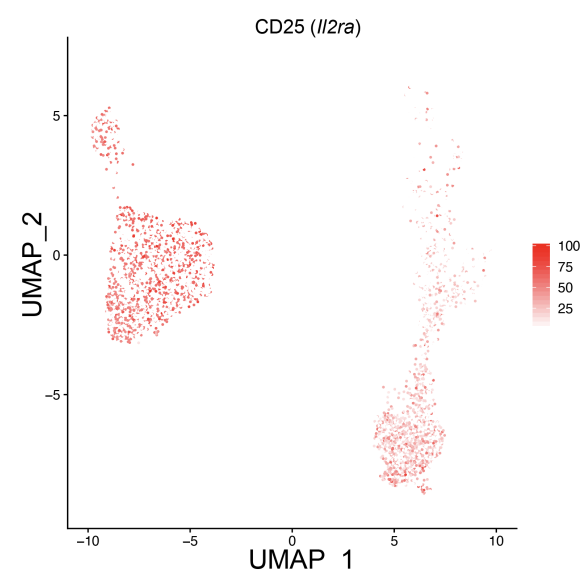

Cells in cluster 0 
Figure 5. WT Trp2/K $\mathrm{K}^{\mathrm{b}}$-specific cells show proliferative defects in the early effector phase Trp2/ $\mathrm{K}^{\mathrm{b}}$-specific CD8+ T cells were isolated from WT and $D c t^{-}$mice on day three after TriVax and submitted for scRNA-seq. After initial processing, the WT and $D c t^{-1-}$ data sets were merged and further analyzed. (A) UMAP representation of gene expression from merged datasets determined using Seurat; each dot represents one cell. Clusters are indicated by color. (B) Cells from the $\mathrm{Dct}^{{ }^{\prime}-}$ sample are shown on the left and cells from the WT sample on the right using the same UMAP projection (generated from merged data) shown in Fig. 6A. (C) The most differentially expressed genes between groups $A$ and $B$ (see Fig. 6A); histone genes and other genes associated with proliferation are indicated. A positive average log fold change value indicates higher expression in group A. (D) Cell cycle analysis indicates the cell cycle phase for each cell on the UMAP plot (cells from the $D c t^{-}$sample are shown on the left and cells from the WT sample on the right). (E) Pie charts show the frequencies of cells within cluster 0 in each stage of the cell cycle (left: $D c t^{\prime-}$ sample, right: WT sample). (F) Expression of CD25 (I/2ra) by cell is indicated on the clusters by color.

381

382

383

384

385

386

387

388

389

390

391

392

393

394

395

396

397

398

399

400

401

402

403

404

405

406

407

408

409

410

411

412

413

414

415
Taken as a whole, the RNA-sequencing data suggest that WT Trp2/Kb-specific cells are deficient in their ability to form the more proliferative subpopulation that comprises a majority of the $D c t^{-}$Trp2 $/ \mathrm{K}^{\mathrm{b}}$-specific population on day three after priming. Nevertheless, proliferation of the WT population was not entirely constrained, since this pool continued to expand over successive days (Figure 4).

\section{$\underline{W T}$ Trp $2 / K^{b}-$ specific cells are inefficient at mediating vitiligo}

$T$ cells that escape self-tolerance mechanisms can sometimes elicit autoimmunity. Even $\mathrm{CD}^{+} \mathrm{T}$ cells with very low affinity TCRs that avoid deletional tolerance have been found to drive tissue destruction following activation (Enouz et al., 2012; Sabatino et al., 2011; Zehn \& Bevan, 2006). Furthermore, vigorous immunization against Trp2 can break tolerance and lead to vitiligo (Bowne et al., 1999; Cho \& Celis, 2009; Moynihan et al., 2016). Our data indicated that the proliferative response of $\operatorname{Trp} 2 / \mathrm{K}^{\mathrm{b}}$-specific cells was only slightly impaired in WT relative to $D c t^{--}$mice, but the ability of these expanded cells to mediate overt tissue damage, as indicated by autoimmune vitiligo, was unclear.

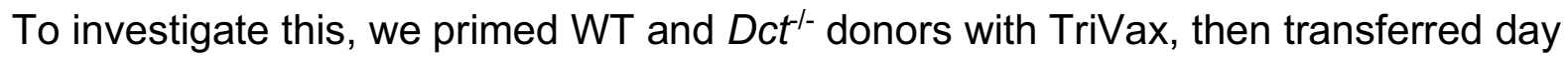
seven effectors to congenically distinct WT recipient mice in parallel and immunized these recipients with TriVax. Equal numbers of $D c t^{--}$and WT cells were transferred to compensate for the reduced response in WT mice. The recipients were treated with dinitrofluorobenzene (DNFB) on the left flank six days after transfer as a local inflammatory stimulus (Haas et al., 1992; Mackay et al., 2012; Zhang et al., 2009); vehicle (acetone/olive oil) was applied to the right flank (Figure 6A). Analysis of the blood six days after transfer and boosting revealed expansion of both types of donor cells; although there was a trend for transferred $D c t^{--}$cells to expand to a greater degree than donor WT cells, the difference was not statistically significant (Figure 6B). Recipient mice were subsequently monitored for vitiligo development on a weekly basis and scored using a numeric metric (Supplemental figure 5A). 
bioRxiv preprint doi: https://doi.org/10.1101/2020.12.16.423036; this version posted December 16, 2020. The copyright holder for this preprint (which was not certified by peer review) is the author/funder, who has granted bioRxiv a license to display the preprint in perpetuity. It is made available under aCC-BY 4.0 International license.

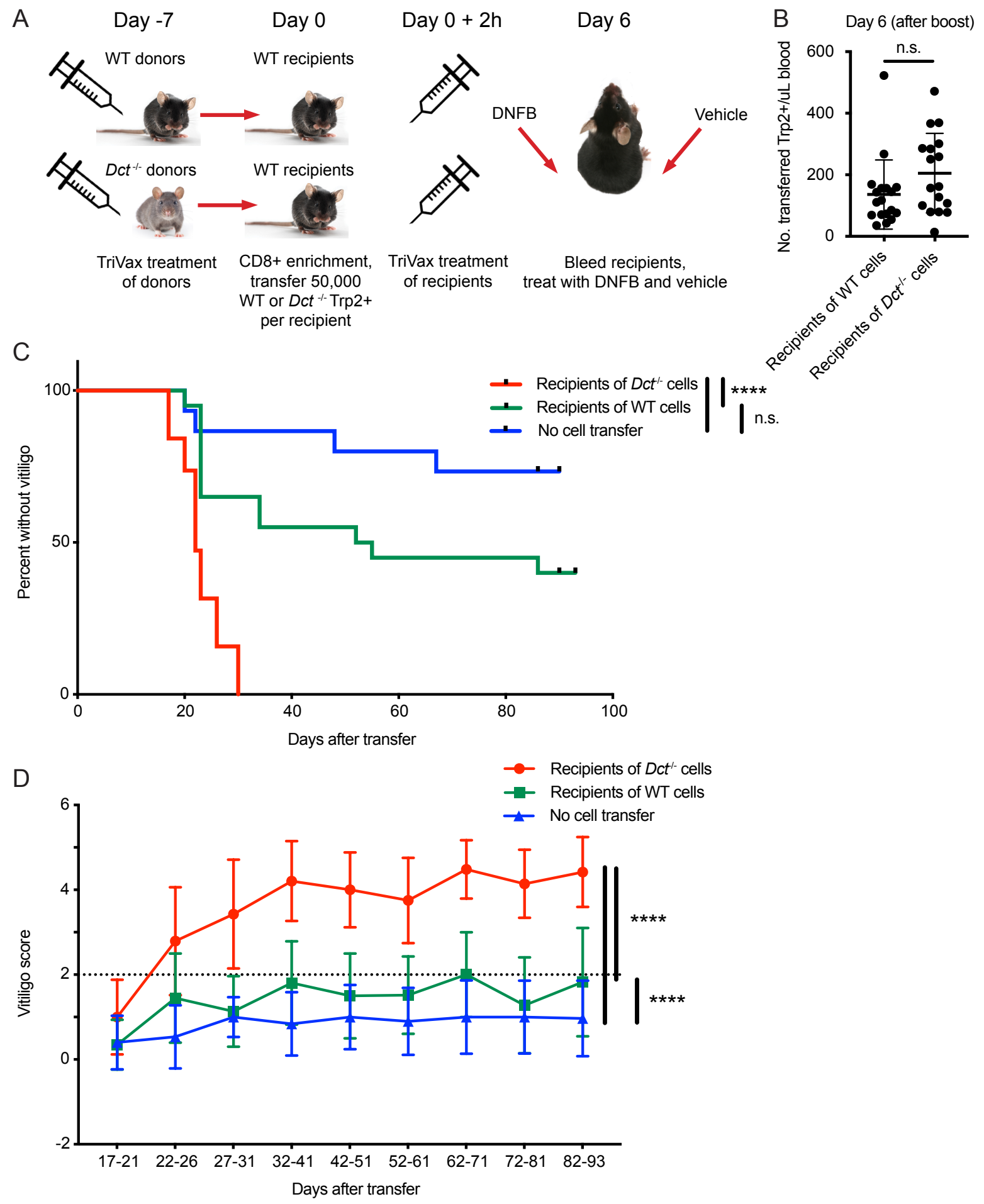


Figure 6. WT Trp2/ $\mathrm{K}^{\mathrm{b}}$-specific cells are unable to mediate efficient anti-melanocyte activity (A) WT mice were monitored for vitiligo after receiving 50,000 Trp2/ $/ \mathrm{K}^{\mathrm{b}}$-specific cells from WT or $D c t^{\prime-}$ donors primed with TriVax seven days prior; recipient mice received TriVax (100 ug Trp2) on the day of transfer and were treated with DNFB (left flank) six days later. No cell transfer controls (not shown in schematic) received TriVax and DNFB but no transferred cells. (B) Recipient mice were bled on day six after transfer and TriVax; the number of transferred Trp2/Kb-positive cells per uL blood is shown. (C) Kaplan Meier curve of vitiligo development; mice were considered to have vitiligo when they first had a vitiligo score of two that was sustained. Mean group vitiligo scores over time are shown in (D), with a dotted line indicating definite vitiligo. Data in $C$ and $D$ are compiled from three experiments with 4-10 mice per group. Data in B are compiled from two experiments with 4-10 mice per group. ${ }^{* * * *} p<$ 0.0001 by unpaired $t$ test $(B)$, log-rank survival analysis $(C)$, or two-way ANOVA followed by Tukey's multiple comparisons test (D).

417 Recipients of $\mathrm{Dct}^{- \text {- }}$ cells developed vitiligo more rapidly and more extensively than mice receiving WT cells, beginning around day 20 after cell transfer (Figure 6C). Vitiligo was most frequently initiated at the DNFB-treated site and would often progress over the following weeks to involve the right flank, hair around the eyes, and-in some caseshair distributed over the body. Vitiligo progressed more rapidly and to a greater extent (higher numeric score) in recipients of $\mathrm{Dct}^{\prime-}$ cells (Figure 6D, Supplemental figures 5B and $5 \mathrm{C}$ ), although low-grade vitiligo was observed in some mice receiving WT Trp2/K ${ }^{\mathrm{b}}$ specific effector cells or TriVax and DNFB without cell transfer. It is possible that initial melanocyte destruction mediated by the transferred cells facilitated antigen release and a broadening of the anti-melanocyte response to include endogenous T cells; nevertheless, preliminary studies using irrelevant TCR transgenic mice (P14) as recipients showed that $\operatorname{Trp} 2 / \mathrm{K}^{\mathrm{b}}$-specific donor cells from $D c t^{--}$mice were still able to induce vitiligo in this setting (data not shown).

Vitiligo severity (average vitiligo score) was positively correlated with the number of donor Trp2/K $\mathrm{K}^{\mathrm{b}}$-specific cells in the blood on day 6 after transfer and TriVax boost (Supplemental figure 5D). This suggests that the enhanced proliferative capacity of Dct I- cells was a factor in their superior ability to induce vitiligo, although it does not rule out additional qualitative differences between the WT and $D c t^{1-}$ populations.

In summary, in contrast to the relatively modest differences in the expansion of $\operatorname{Trp} 2 / \mathrm{K}^{\mathrm{b}}$ responders in WT and $D c t^{/-}$mice, the ability of these populations to mediate 


\section{Discussion}

A number of groups have demonstrated the existence of self-reactive CD8+ and CD4+ T cells in the periphery of mice and healthy human adults (Anderson et al., 2000; Bloom et al., 1997; Delluc et al., 2010; Maeda et al., 2014; Su et al., 2013; Yu et al., 2015). In some cases, self-reactive cells display indicators of reduced functionality, revealing them as tolerant and unlikely to cause spontaneous pathology. For example, selfreactive cells are often reported to express inhibitory receptors such as CTLA-4, PD-1, and LAG-3 (Fife \& Bluestone, 2008; Maeda et al., 2014; Nelson et al., 2019; Schietinger et al., 2012). However, studies in human adults have identified self-reactive cells with a phenotype similar to that of naïve CD8+ T cells specific for foreign antigens (Yu et al., 2015); these cells did not display an overtly anergic phenotype but still responded poorly to stimulation. It is important to understand the mechanisms restraining these cells under normal conditions as well as their potential to cause pathology; such knowledge is critical to designing effective therapies to restrain these cells (e.g., to control autoimmune disease) or induce their responses (e.g., for cancer immunotherapy). As described in this report, we developed a polyclonal mouse model for non-deletional self-tolerance, enabling us to define the characteristics of these cells and their reactivity in a physiological setting.

We found that the pre-immune population of Trp2/Kb-specific cells in WT and Dct/strains were qualitatively similar, sharing a naïve phenotype and indistinguishable gene expression profile; there were no clear signs of prior antigen exposure among the WT cells. The size of the Trp2/K $\mathrm{K}^{\mathrm{b}}$-specific precursor pool was only slightly (although significantly) smaller in WT mice and the response to Trp2 immunization was substantial in both strains, leading to a $>1000$-fold expansion of Trp2/ $\mathrm{K}^{\mathrm{b}}$-specific cells in both WT and $D c t^{-1}$ mice. Despite these commonalities, cells primed in $D c t^{1-}$ mice proliferated more extensively and were capable of much more rapid and widespread tissue destruction, read out as vitiligo, after adoptive transfer.

Our adoptive transfer studies showed that the observed restraint in the WT Trp2/K specific response did not depend on extrinsic factors but was a cell-intrinsic feature of pre-immune $\mathrm{CD}^{+} \mathrm{T}$ cells. This implies that other cell populations, including CD4+ Tregs or regulatory CD8+ T cells (Saligrama et al., 2019) are neither required for nor capable of affecting the responses of tolerant and non-tolerant Trp2/Kb-specific cells during priming. These findings also effectively eliminate the possibility that self-antigen presentation during Trp2 priming alters the nature of the immune response. However, while our studies argue that cell-extrinsic regulation is not required for enforcement or maintenance of tolerance by $\operatorname{Trp} 2 / \mathrm{K}^{\mathrm{b}}$-specific cells, this does not exclude a potential role for regulatory T cell populations in establishing the initial tolerant state in WT mice. It is currently unclear whether tolerance to Trp2 is enforced during thymic development or in the periphery of WT mice: one report suggested that Dct expression is undetectable in thymic mTECs (Träger et al., 2012), but Trp2 could be brought into the thymus by dendritic cell populations to induce tolerance in WT animals. The site of tolerance induction was not a focus of the current study, but it will be interesting to determine whether instances of non-deletional $\mathrm{CD}^{+} \mathrm{T}$ cell self-tolerance correlate with self- 
antigen expression patterns in the thymus (e.g., AIRE-regulated tissue-specific antigen expression).

Many of the characteristics we report for Trp2/K $\mathrm{K}^{\mathrm{b}}$-specific $\mathrm{CD} 8^{+} \mathrm{T}$ cells in WT mice are strongly reminiscent of T cells with low affinity/avidity for antigen (Bouneaud et al., 2000; Enouz et al., 2012; Zehn \& Bevan, 2006; Zehn et al., 2009), and we did observe modestly higher Trp2 $/ \mathrm{K}^{\mathrm{b}}$ tetramer staining intensity on a subset of $D c t^{-{ }^{-}}$cells compared to WT responder cells. However, these differences were not progressively magnified as the immune response developed, arguing against a noticeable outgrowth of higher affinity/avidity TCR clones in $D c t^{-1}$ animals, as might have been expected if TCR affinity was the primary factor driving improved proliferation in the $D c t^{--}$population. Indeed, the relatively subtle differences in Trp $2 / \mathrm{K}^{\mathrm{b}}$ tetramer staining that we were able to detect in this optimized experimental model would not likely be sufficient to predict self-reactivity versus tolerance in a less controlled setting.

Other studies utilizing mouse models have reported that even CD8 ${ }^{+} \mathrm{T}$ cells with very low affinity/avidity TCRs (including those undetectable by normal peptide/MHC tetramer staining) can provoke overt tissue damage (Enouz et al., 2012; Sabatino et al., 2011; Zehn \& Bevan, 2006), in some cases at levels comparable to or greater than that induced by non-tolerant and/or higher affinity cells. Our data indicate that the opposite can also occur: despite largely overlapping tetramer staining profiles, WT and Dct ${ }^{1-}$ Trp2/K $/ \mathrm{K}^{\mathrm{b}}$-specific cells exhibit markedly different abilities to mediate widespread vitiligo. Hence, the impact of $\mathrm{CD}^{+} \mathrm{T}$ cell tolerance toward some self-antigens only partially limits expansion but can prevent the generation of cells readily capable of potent tissue destruction: tolerance is not a binary state.

A goal of this work was to define which characteristics, if any, could be associated with self-tolerant $\mathrm{CD}^{+} \mathrm{T}$ cells that escape clonal deletion. Unexpectedly, we found that multiple measures - the enumeration, peptide/MHC tetramer staining intensity, phenotype, and gene expression of pre-immune cells as well as the ability of these cells to proliferate following immunogenic exposure to self-antigens-failed to provide a robust metric for distinguishing $\mathrm{CD}^{+} \mathrm{T}$ cells that are functionally tolerant (i.e., unlikely to cause autoimmune pathology) versus non-tolerant (i.e., have a high propensity to induce autoimmunity). This finding highlights the limitations of currently available assays for accurately predicting responsiveness to self-antigens.

However, we were able to delineate an inflection point following priming at which the responses of tolerant and non-tolerant cells diverged. Flow cytometry and single-cell RNA sequencing of Trp $2 / \mathrm{K}^{\mathrm{b}}$-specific $\mathrm{CD}^{+} \mathrm{T}$ cells soon after priming demonstrated that WT responders failed to differentiate into a CD25+, IRF4+ population (a characteristic of most $D c t^{\prime-}$ responder cells) and indicated that WT cells showed poor commitment to sustained proliferation. These combined features may be useful for further defining the responses by self-antigen specific cells that are or are not capable of overt tissue destruction. 
The early effector population of $\operatorname{Trp} 2 / \mathrm{K}^{\mathrm{b}}$-specific cells demonstrates heterogeneity on a transcriptomic level in both strains. Whereas the majority of $D c t^{-1}$ cells show a highly proliferative phenotype characterized by active cell cycling and responsiveness to mTOR and Myc, few WT Trp2/Kb-specific cells fall into this group. The reason(s) underlying the inability of WT cells to optimally engage these important pathways and proliferate efficiently requires further investigation but may relate to impaired sensitivity to endogenous IL-2 or other cytokines, the composition of the TCR repertoire, and/or altered TCR signaling. How these or other factors relate to the relative inability of primed WT Trp2/K $\mathrm{K}^{\mathrm{b}}$-specific cells to mediate overt tissue damage is currently unclear, but it will be critical to identify the cellular and molecular mechanisms involved in future studies. Ongoing and future work will address the TCR repertoire and downstream signaling, metabolic characteristics, and epigenetic landscape of WT versus $D c t^{-1}$ Trp2/Kb-specific cells. Recent studies on dysfunctional tumor-specific or exhausted CD8+ T cells have shown that epigenetic changes in chromatin accessibility or methylation can maintain such states (Ghoneim et al., 2017; Pauken et al., 2016; Philip et al., 2017), which could explain the cell-intrinsic nature of the tolerance seen in our model.

We were able to identify CD8+ T cells specific for other melanocyte epitopes/antigens in pre-immune mice; these cells had a similar phenotype to WT Trp $2 / \mathrm{K}^{\mathrm{b}}$-specific cells. Accordingly, we predict that our results will apply to other populations of CD8+ T cells specific for melanocyte and potentially other tissue-restricted antigens. Similar populations of self-specific $\mathrm{CD}^{+} \mathrm{T}$ cells may exist in humans, and the ability of such cells to respond to self-antigen immunization while not causing autoimmune damage is relevant for understanding the limits of "breaking" tolerance, e.g., for cancer immunotherapy. Indeed, our results align with work examining polyclonal self-antigenspecific cells in human adults (Yu et al., 2015) with regard to the phenotype (modestly lower tetramer MFI, lower CD25 expression) and response to cognate peptide (diminished) observed among tolerant cells. Another study examining self-specific CD8 ${ }^{+}$ T cells (Maeda et al., 2014) attributed their restrained responsiveness to Treg-mediated suppression; while we did not detect a cell-extrinsic regulatory mechanism in our studies, it is certainly possible that this mechanism limits the response to some selfantigens.

Our finding that polyclonal melanocyte-specific cells exhibit covert cell-intrinsic tolerance characterized by a partial defect in proliferation and a profound defect in tissue damage has implications for utilizing such cells therapeutically. This model has clear relevance to human physiology and will be useful in exploring methods of correcting the proliferative defects of tolerant cells to more effectively mobilize them in cancer immunotherapy approaches targeting tumor antigens shared with self. 


\section{Materials and methods}

575

576

577

578

579

580

581

582

583

584

585

586

587

588

589

590

591

592

593

594

595

596

597

598

599

600

601

602

603

604

605

606

607

608

609

610

611

612

613

614

615

616

617

618

\section{Mice}

C57BL/6 (WT) mice were obtained from Charles River laboratories and housed in specific pathogen-free conditions at the University of Minnesota. Dct ${ }^{-1}$ mice on a C57BL/6 background were developed by A. Andy Hurwitz when at the $\mathrm{NCl}$; the mice were subsequently bred in-house on different congenic backgrounds and housed in specific pathogen-free conditions. Animals were used at 6-14 weeks of age. All animal experiments were approved by the Institutional Animal Care and Use Committee at the University of Minnesota. In accordance with $\mathrm{NIH}$ guidelines, both male and female animals were used in experiments; males are indicated by square symbols in the figures.

\section{Tetramer enrichment}

Tetramer enrichment was used to isolate antigen-specific cells from pre-immune or acutely challenged mice. A modification of the method used by Obar et al. (Obar et al., 2008) was employed. Following digestion with collagenase D, single-cell suspensions were prepared from the spleens (acutely challenged mice) or spleen and peripheral/mesenteric lymph nodes (pre-immune mice). When possible, the same tetramer (Trp2 $180-188 / K^{b}$ ) was used in both APC and PE to ensure specificity. Anti-PE and anti-APC beads and magnetized columns (both from Miltenyi Biotec) were used to enrich for tetramer-bound cells. Samples were stained and analyzed by flow cytometry; CountBright counting beads (Invitrogen) were used for enumeration.

\section{In vivo priming with Trp2}

TriVax immunization was used as previously described (Cho \& Celis, 2009); mice were immunized intravenously (via tail vein injections) with Trp2180-188 peptide or Trp2 and B8R $_{20-27}$ peptides, agonist-anti CD40 antibody (BioXCell), and vaccine-grade poly(l:C), a toll-like receptor 3 agonist (InvivoGen). Peptide doses of 50, 100, and $200 \mu$ g were used for effector timepoints, transfer experiments, and acute timepoints, respectively. Animals that received TriVax immunization via intraperitoneal instead of intravenous injection were removed from the analysis.

\section{Infections with LmTrp2}

Frozen stocks of LmTrp2 (Bruhn et al., 2005) were thawed and grown to log-phase in tryptic soy broth supplemented with streptomycin $(50 \mu \mathrm{g} / \mathrm{mL})$. Mice were typically injected with approximately $10^{5}-10^{6}$ colony-forming units intravenously or intraperitoneally. Infectious doses were verified by colony counts on tryptic soy brothstreptomycin plates.

\section{Ex vivo stimulation}

In some experiments, splenocytes were stimulated ex vivo after isolation from infected mice. Splenocytes were incubated with Trp2 peptide $\left(10^{-6} \mathrm{M}\right)$ and Golgiplug (BD Biosciences) for $4-6$ hours at $37^{\circ} \mathrm{C}$; parallel wells with no peptide were used as a control. Cells were washed and stained with surface antibodies, followed by fixation and 
permeabilization with a FoxP3 Fix/Perm kit (eBioscience) or FoxP3/transcription factor staining buffer kit (Tonbo Biosciences) and staining with intracellular antibodies.

Adoptive transfer experiments

Bulk polyclonal CD8+ T cells were isolated from the spleen and lymph nodes of WT or $\mathrm{Dct}^{-1}$ mice using negative magnetic enrichment (CD8a+ T cell Isolation Kit; Miltenyi Biotec). Enriched CD8+ T cells (typically $\sim 75-90 \%$ pure) were resuspended in sterile PBS and 2-2.5 x 106 CD8+ T cells were injected intravenously per recipient mouse; recipient mice were congenically distinct. One day later, the recipient mice were immunized with TriVax or LmTrp2 intravenously or intraperitoneally. Mice were sacrificed for analysis seven days later.

\section{Bulk RNA sequencing of pre-immune mice}

$\operatorname{Trp} 2 / \mathrm{K}^{\mathrm{b}}$-specific cells were isolated from pre-immune WT and $D c t^{--}$mice using tetramer enrichment followed by fluorescence-activated cell sorting on double tetramer positive cells. Cells were isolated from three separate cohorts, with each cohort comprising eight WT and eight $D c t^{--}$mice. The Clontech StrandedRNA Pico Mammalian workflow was used for library preparation, and samples were sequenced using an Illumina NextSeq instrument (2x75 bp paired end reads).

\section{Bulk RNAseq analysis}

Raw sequencing data were demultiplexed by sample into FASTQs (mean 24.6 million reads/sample) and mapped against the mouse genome (Ensembl GRCm38 release 95) using Hisat2 software (v 2.1.0). Gene level quantification was completed using Subread featureCounts software $(v 1.6 .2)$ and the read counts table was processed in $\mathrm{R}(\mathrm{v}$ 3.5.2). Differentially expressed genes were identified with DESeq2 software ( $v$ 1.22.2) using a negative binomial model with effect size estimation completed by apeglm algorithm via the IfcShrink function. Group comparison p-values were adjusted by the Benjamini and Hochberg method to account for multiple hypothesis testing where genes with a false discovery rate (FDR) $q<0.05$ were investigated in downstream analyses. WT and $D c t^{--}$mice were primed with $\operatorname{TriVax}(200 \mu \mathrm{g} \operatorname{Trp} 2)$, and $\operatorname{Trp} 2 / \mathrm{K}^{\mathrm{b}}$-specific cells were isolated on day three using tetramer enrichment followed by fluorescenceactivated cell sorting. Cells were submitted for barcoding and library preparation using the 10x Genomics platform (Chromium Single Cell 5' Library \& Gel Bead Kit) (Zheng et al., 2017) and each sample was sequenced using an Illumina NovaSeq instrument with 2x150 bp paired end protocol.

Raw sequencing data were pro

660 Raw sequencing data were processed using Cell Ranger (v 3.0.2; 10x Genomics)

661 software programs "mkfastq" for demultiplexing the WT and Dct ${ }^{\text {- }}$ Illumina libraries and

662 "count" for read alignment against the mouse genome (mm10, provided by 10x

663 Genomics, ver 3.0.0) and generation of the mRNA transcript count table. Raw count

664 data were loaded into R (v 3.6.1) and analyzed with the Seurat R package ( $v$ 
665 3.0.3.9039) (Butler et al., 2018; Stuart et al., 2019). Each scRNA dataset (WT or Dct ${ }^{-1}$ ) was independently filtered to include only cells (i.e. uniquely barcoded transcripts) expressing more than 300 genes and genes expressed in more than 3 cells (e.g. counts $>0$ ). The proportion of mitochondrial RNA in each cell was calculated and cells with extreme levels (top or bottom $2 \%$ of all cells) were removed from the analysis. Genes with extreme expression levels (top or bottom $1 \%$ of all genes) were removed. Contaminating cells expressing high levels of B cell or myeloid lineage marker genes and low levels of $T$ cell markers were removed using empirically derived thresholds (675 $\mathrm{B}$ cells and 26 myeloid cells removed from WT and $117 \mathrm{~B}$ cells removed from $\left.D c t^{-}\right)$. A total of 4,539 WT cells $\left(19,326\right.$ genes) and 11,680 $\mathrm{Dct}^{{ }^{-}}$cells (19,416 genes) were analyzed downstream. Raw RNA counts were normalized with the LogNormalize function and each cell was classified according to its expression of canonical cell cycle genes using the CellCycleScoring function (gene sets provided in Seurat). Raw RNA counts were normalized and transformed using the Seurat SCTransform function (Hafemeister \& Satija, 2019) including the percent of mitochondria expression and cell cycle S/G2M-phase scores as regression factors. Principal components analysis (PCA) was performed using the normalized, mean-centered, and scaled SCT dataset (RunPCA function). The top 3000 variable genes from each dataset were identified using the FindVariableFeatures function (vst method) and were used for WT and Dctsample integration (Stuart et al., 2019). Two-dimensional projections were generated using the top 30 PCA vectors as input to the RunTSNE and RunUMAP functions. Cells were clustered using the FindNeighbors (top 30 PCA vectors) and FindClusters functions (testing a range of possible resolutions: $0.2,0.4,0.8,1.2,1.6$ ). Pairwise differential gene expression (DE) testing (Wilcox rank-sum) with the FindMarkers function was performed between all initial clusters; any two clusters were merged if there were fewer than 5 significant DE genes (i.e. absolute value of log2-fold-change $>=$ 0.25 and Bonferroni adjusted $p$-value $<=0.01$ ). Pairwise DE testing continued on subsequently merged clusters. A final resolution of 0.2 was chosen (merging of initial clusters by $D E$ testing was not required) to best represent the biological processes within the dataset. Cluster-specific pathway expression testing was completed using the VISION R package (DeTomaso et al., 2019) and figures were generated using the ggplot2 R package (Wickham, 2016). Gene Set Enrichment Analysis (Mootha et al., 2003; Subramanian et al., 2005) was performed using pre-ranked gene lists (sorted from largest to smallest log2 fold change between clusters compared). Gene set enrichment statistics were calculated for two gene set collections in the Molecular Signatures Database (hallmarks and c2 curated) derived for mouse symbols using the $R$ package msigdbr, v 6.2.1 using the $R$ package clusterProfiler ( $v$ 3.12.0). Interesting gene sets with a FDR $q<0.05$ were evaluated. Raw and processed data have been deposited at Gene Expression Omnibus and are available via GEO.

\section{IL2 complex treatment}

$10 \mu \mathrm{g}$ antibody (S4B6-1; Bio XCell) plus 1 ug murine recombinant carrier-free murine IL2 (R\&D) was administered per mouse via intraperitoneal injection on day 5 after priming with TriVax or LmTrp2; control mice received an equal volume of PBS. 


\section{Vitiligo induction}

712 Donor mice (WT and $D c t^{--}$) were primed with TriVax (100 $\mu \mathrm{g}$ Trp2); in one experiment,

713 donor mice received $\sim 50 \%$ less of the other TriVax components to minimize adverse reactions. Negative enrichment for CD8+ T cells was performed on day seven. Live cells were counted using a hemocytometer, and the percentages of CD8+ and Trp2/K tetramer-binding cells were applied to enumerate Trp $2 / \mathrm{K}^{\mathrm{b}}$-specific cells; equal numbers $(50,000)$ of WT or $D c t^{-1}$ Trp2/Kb-specific cells were transferred to WT recipients. Recipients were treated with TriVax (100 $\mu \mathrm{g}$ Trp2) later the same day. On day six after cell transfer, the recipients were bled to assess donor populations. The mice were then treated with dinitrofluorobenzene (DNFB; $0.15 \%$ in $4: 1$ acetone:olive oil) on the left flank; $30 \mu \mathrm{L}$ was applied to a shaved patch of skin $\sim 1.5 \times 1.5 \mathrm{~cm}$ in size. $30 \mu \mathrm{L}$ of vehicle was applied to the right flank in the same manner. Control mice did not receive cell transfers, but did receive TriVax immunization and DNFB treatment at the same time as mice receiving cell transfers. Mice were monitored for vitiligo development on a weekly basis by an observer blinded to the experimental groups.

726

727

728

729

730

731

732

733

734

735

736

737

738

739

740

741

742

743

744

745

746

747

748

749

750

751

752

753

754

755

756

\section{Tetramers and flow cytometry}

$\mathrm{H}-2 \mathrm{~K}^{\mathrm{b}}$ tetramers loaded with $\operatorname{Trp} 2{ }_{180-188}$ or $\mathrm{B} 8 \mathrm{R}_{20-27}$ were obtained from the $\mathrm{NIH}$ tetramer core facility and labelled with streptavidin-fluorophore conjugates in house. Single-cell suspensions were stained with tetramers (when applicable) and fluorescent dyeconjugated antibodies purchased from BD Biosciences, Tonbo Biosciences, eBioscience, or BioLegend. In many experiments, Live/Dead Fixable Aqua Dead Cell Stain Kit (ThermoFisher Scientific) was used for dead cell exclusion. When applicable, cells were fixed with a FoxP3 Fix/Perm kit (eBioscience) or FoxP3/transcription factor staining buffer kit (Tonbo Biosciences). These kits were also used for permeabilization prior to staining with intracellular antibodies. Samples were run on a BD LSR II or BD Fortessa instrument using BD FACSDiva (BD Bioscience), and data were analyzed with FlowJo (BD).

\section{Statistical analysis}

Prism software (GraphPad) was used to plot data and conduct statistical analyses. An unpaired t test was used for two-way comparisons between two groups. A one-way ANOVA with Sidak's or Tukey's multiple comparisons test was used when multiple comparisons were performed. Log-rank (Mantel-Cox) tests were used to evaluate Kaplan-Meier curves. A two-way ANOVA with Tukey's multiple comparisons test was used to evaluated vitiligo scores over time. P-values are represented as follows: ${ }^{*} p<$ $0.05,{ }^{* *} p<0.01,{ }^{* * *} p<0.001,{ }^{* * *} p<0.0001$.

\section{Supplemental material}

Fig. S1 shows additional analysis of the Trp2/ $\mathrm{K}^{\mathrm{b}}$-specific population and cells specific for other melanocyte epitopes in pre-immune mice. Fig. S2 presents data using LmTrp2 as an alternative method of stimulating with Trp2. Fig. S3 shows overlays of tetramer staining at various time points after TriVax immunization, along with the acute response to in vivo stimulation with Trp2 peptide alone. Gene set enrichment analysis of single- 
cell data and the response of WT and KO Trp2/ $\mathrm{K}^{\mathrm{b}}$-specific cells to IL-2C are presented in Fig. S4. Fig. S5 shows the vitiligo scoring metric and correlation analysis of the average vitiligo score relative to the number of transferred $T r p 2 / K^{b}$-specific cells following transfer and boosting.

\section{Author contributions}

ENT, KRR, and SCJ designed experiments and interpreted results. ENT, KSB, HBdS, $\mathrm{KEB}$, and KRR performed experiments, and ENT analyzed results. TPK performed bioinformatics analysis of RNAseq data and wrote the relevant portions of the Methods section. AAH and KRS created the Dct-deficient mouse strain. RBF performed initial experiments leading to these studies and provided guidance. ENT and SCJ wrote the manuscript, with all authors contributing to edits.

\section{Acknowledgments}

We thank members of the Jamequist lab for helpful discussions and technical assistance. We thank the UMN Flow Cytometry Resource for cell sorting, the UMN Genomics Center for assistance with sequencing experiments, and the NIH tetramer core for peptide/MHC monomers. We thank the Celis and Restifo labs for providing reagents and samples used in enumerating cells specific for alternative melanocyte epitopes. We thank Dietmar Zehn for reviewing an early draft of this manuscript.

This work was supported by NIH grants P01 Al035296 (SCJ), R01 Al140631 (SCJ), and T32 OD010993 (ENT).

\section{Competing interests}

The authors declare no competing financial interests. 


\section{References}

Anderson, A. C., Nicholson, L. B., Legge, K. L., Turchin, V., Zaghouani, H., \& Kuchroo, V. K. (2000). High frequency of autoreactive myelin proteolipid protein-specific T cells in the periphery of naive mice: mechanisms of selection of the self-reactive repertoire. J Exp Med, 191(5), 761-770.

Avogadri, F., Gnjatic, S., Tassello, J., Frosina, D., Hanson, N., Laudenbach, M., . . Jungbluth, A. A. (2016). Protein Expression Analysis of Melanocyte Differentiation Antigen TRP-2. Am J Dermatopathol, 38(3), 201-207. doi:10.1097/DAD.0000000000000362

Azzam, H. S., Grinberg, A., Lui, K., Shen, H., Shores, E. W., \& Love, P. E. (1998). CD5 expression is developmentally regulated by T cell receptor (TCR) signals and TCR avidity. J Exp Med, 188(12), 2301-2311. doi:10.1084/jem.188.12.2301

Bloom, M. B., PerryLalley, D., Robbins, P. F., Li, Y., ElGamil, M., Rosenberg, S. A., \& Yang, J. C. (1997). Identification of tyrosinase-related protein 2 as a tumor rejection antigen for the B16 melanoma. Journal of Experimental Medicine, 185(3), 453-459. doi:10.1084/jem.185.3.453

Bouneaud, C., Kourilsky, P., \& Bousso, P. (2000). Impact of negative selection on the T cell repertoire reactive to a self-peptide: A large fraction of T cell clones escapes clonal deletion. Immunity, 13(6), 829-840. doi:10.1016/s1074-7613(00)00080-7

Bowne, W. B., Srinivasan, R., Wolchok, J. D., Hawkins, W. G., Blachere, N. E., Dyall, R., . . . Houghton, A. N. (1999). Coupling and uncoupling of tumor immunity and autoimmunity. J Exp Med, 190(11), 1717-1722.

Bruhn, K. W., Craft, N., Nguyen, B. D., Yip, J., \& Miller, J. F. (2005). Characterization of anti-self CD8 T-cell responses stimulated by recombinant Listeria monocytogenes expressing the melanoma antigen TRP-2. Vaccine, 23(33), 4263-4272. doi:10.1016/j.vaccine.2005.02.018

Butler, A., Hoffman, P., Smibert, P., Papalexi, E., \& Satija, R. (2018). Integrating single-cell transcriptomic data across different conditions, technologies, and species. Nat Biotechnol, 36(5), 411-420. doi:10.1038/nbt.4096

Byrne, K. T., Côté, A. L., Zhang, P., Steinberg, S. M., Guo, Y., Allie, R., . . Turk, M. J. (2011). Autoimmune melanocyte destruction is required for robust $\mathrm{CD} 8+$ memory $\mathrm{T}$ cell responses to mouse melanoma. J Clin Invest, 121(5), 1797-1809. doi:10.1172/JCI44849

Cai, Z., Kishimoto, H., Brunmark, A., Jackson, M. R., Peterson, P. A., \& Sprent, J. (1997). Requirements for peptide-induced T cell receptor downregulation on naive CD8+ T cells. J Exp Med, 185(4), 641-651.

Cheng, M., \& Anderson, M. S. (2018). Thymic tolerance as a key brake on autoimmunity. Nat Immunol, 19(7), 659-664. doi:10.1038/s41590-018-0128-9

Cho, H. I., \& Celis, E. (2009). Optimized Peptide Vaccines Eliciting Extensive CD8 T-Cell Responses with Therapeutic Antitumor Effects. Cancer Research, 69(23), 9012-9019. doi:10.1158/0008-5472.can-09-2019 
832

833

834

835

836

837

838

839

840

841

842

843

844

845

846

847

848

849

850

851

852

853

854

855

856

857

858

859

860

861

862

863

864

865

866

867

868

Daniels, M. A., \& Jameson, S. C. (2000). Critical role for CD8 in T cell receptor binding and activation by peptide/major histocompatibility complex multimers. J Exp Med, 191(2), 335-346. doi:10.1084/jem.191.2.335

Daniels, M. A., Teixeiro, E., Gill, J., Hausmann, B., Roubaty, D., Holmberg, K., . . Palmer, E. (2006). Thymic selection threshold defined by compartmentalization of Ras/MAPK signalling. Nature, 444(7120), 724-729. doi:10.1038/nature05269

Delluc, S., Ravot, G., \& Maillere, B. (2010). Quantification of the preexisting CD4 T-cell repertoire specific for human erythropoietin reveals its immunogenicity potential. Blood, 116(22), 4542-4545. doi:10.1182/blood-2010-04-280875

DeTomaso, D., Jones, M. G., Subramaniam, M., Ashuach, T., Ye, C. J., \& Yosef, N. (2019). Functional interpretation of single cell similarity maps. Nat Commun, 10(1), 4376. doi:10.1038/s41467-019-12235-0

Enouz, S., Carrié, L., Merkler, D., Bevan, M. J., \& Zehn, D. (2012). Autoreactive T cells bypass negative selection and respond to self-antigen stimulation during infection. $J$ Exp Med, 209(10), 1769-1779. doi:10.1084/jem.20120905

Fife, B. T., \& Bluestone, J. A. (2008). Control of peripheral T-cell tolerance and autoimmunity via the CTLA-4 and PD-1 pathways. Immunol Rev, 224, 166-182. doi:10.1111/j.1600065X.2008.00662.x

Fulton, R. B., Hamilton, S. E., Xing, Y., Best, J. A., Goldrath, A. W., Hogquist, K. A., \& Jameson, S. C. (2015). The TCR's sensitivity to self peptide-MHC dictates the ability of naive CD8(+) T cells to respond to foreign antigens. Nature Immunology, 16(1), 107-+. doi:10.1038/ni.3043

Ghoneim, H. E., Fan, Y., Moustaki, A., Abdelsamed, H. A., Dash, P., Dogra, P., . . . Youngblood, B. (2017). De Novo Epigenetic Programs Inhibit PD-1 Blockade-Mediated T Cell Rejuvenation. Cell, 170(1), 142-157.e119. doi:10.1016/j.cell.2017.06.007

Guyonneau, L., Murisier, F., Rossier, A., Moulin, A., \& Beermann, F. (2004). Melanocytes and pigmentation are affected in dopachrome tautomerase knockout mice. Mol Cell Biol, 24(8), 3396-3403. doi:10.1128/mcb.24.8.3396-3403.2004

Haas, J., Lipkow, T., Mohamadzadeh, M., Kolde, G., \& Knop, J. (1992). Induction of inflammatory cytokines in murine keratinocytes upon in vivo stimulation with contact sensitizers and tolerizing analogues. Exp Dermatol, 1(2), 76-83. doi:10.1111/j.16000625.1992.tb00075.x

Hafemeister, C., \& Satija, R. (2019). Normalization and variance stabilization of single-cell RNAseq data using regularized negative binomial regression. Genome Biol, 20(1), 296. doi:10.1186/s13059-019-1874-1

Hogquist, K. A., Baldwin, T. A., \& Jameson, S. C. (2005). Central tolerance: Learning selfcontrol in the thymus. Nature Reviews Immunology, 5(10), 772-782. doi:10.1038/nri1707 
869

870

871

872

873

874

875

876

877

878

879

880

881

882

883

884

885

886

887

888

889

890

891

892

893

894

895

896

897

898

899

900

901

902

903

904

905

906

Ji, Q., Gondek, D., \& Hurwitz, A. A. (2005). Provision of granulocyte-macrophage colonystimulating factor converts an autoimmune response to a self-antigen into an antitumor response. J Immunol, 175(3), 1456-1463. doi:10.4049/jimmunol.175.3.1456

Kappler, J. W., Roehm, N., \& Marrack, P. (1987). T cell tolerance by clonal elimination in the thymus. Cell, 49(2), 273-280. doi:10.1016/0092-8674(87)90568-x

Liu, H. P., Moynihan, K. D., Zheng, Y. R., Szeto, G. L., Li, A. V., Huang, B., . . Irvine, D. J. (2014). Structure-based programming of lymph-node targeting in molecular vaccines. Nature, 507(7493), 519-+. doi:10.1038/nature12978

Mackay, L. K., Stock, A. T., Ma, J. Z., Jones, C. M., Kent, S. J., Mueller, S. N., . . Gebhardt, T. (2012). Long-lived epithelial immunity by tissue-resident memory T (TRM) cells in the absence of persisting local antigen presentation. Proc Natl Acad Sci U S A, 109(18), 7037-7042. doi:10.1073/pnas.1202288109

Maeda, Y., Nishikawa, H., Sugiyama, D., Ha, D., Hamaguchi, M., Saito, T., ... Sakaguchi, S. (2014). Detection of self-reactive CD8(+) T cells with an anergic phenotype in healthy individuals. Science, 346(6216), 1536-1540. doi:10.1126/science.aaa1292

McWilliams, J. A., McGurran, S. M., Dow, S. W., Slansky, J. E., \& Kedl, R. M. (2006). A modified tyrosinase-related protein 2 epitope generates high-affinity tumor-specific $T$ cells but does not mediate therapeutic efficacy in an intradermal tumor model. $J$ Immunol, 177(1), 155-161. doi:10.4049/jimmunol.177.1.155

Mei, Q., Huang, J., Chen, W., Tang, J., Xu, C., Yu, Q., . . Li, S. (2017). Regulation of DNA replication-coupled histone gene expression. Oncotarget, 8(55), 95005-95022. doi:10.18632/oncotarget.21887

Mescher, M. F., Agarwal, P., Casey, K. A., Hammerbeck, C. D., Xiao, Z. G., \& Curtsinger, J. M. (2007). Molecular basis for checkpoints in the CD8 T cell response: Tolerance versus activation. Seminars in Immunology, 19(3), 153-161. doi:10.1016/j.smim.2007.02.007

Mootha, V. K., Lindgren, C. M., Eriksson, K. F., Subramanian, A., Sihag, S., Lehar, J., . . . Groop, L. C. (2003). PGC-1alpha-responsive genes involved in oxidative phosphorylation are coordinately downregulated in human diabetes. Nat Genet, 34(3), 267-273. doi:10.1038/ng1180

Moynihan, K. D., Opel, C. F., Szeto, G. L., Tzeng, A., Zhu, E. F., Engreitz, J. M., . . Irvine, D. J. (2016). Eradication of large established tumors in mice by combination immunotherapy that engages innate and adaptive immune responses. Nat Med, 22(12), 1402-1410. doi: $10.1038 / \mathrm{nm} .4200$

Mueller, D. L. (2010). Mechanisms maintaining peripheral tolerance. Nature Immunology, 11(1), 21-27. doi:10.1038/ni.1817

Nelson, C. E., Mills, L. J., McCurtain, J. L., Thompson, E. A., Seelig, D. M., Bhela, S., . . Vezys, V. (2019). Reprogramming responsiveness to checkpoint blockade in dysfunctional CD8 T cells. Proc Natl Acad Sci U S A. doi:10.1073/pnas.1810326116 
907

908

909

910

911

912

913

914

915

916

917

918

919

920

921

922

923

924

925

926

927

928

929

930

931

932

933

934

935

936

937

938

939

940

941

942

943

944

Obar, J. J., Khanna, K. M., \& Lefrançois, L. (2008). Endogenous naive CD8+ T cell precursor frequency regulates primary and memory responses to infection. Immunity, 28(6), 859869. doi:10.1016/j.immuni.2008.04.010

Obar, J. J., Molloy, M. J., Jellison, E. R., Stoklasek, T. A., Zhang, W., Usherwood, E. J., \& Lefrançois, L. (2010). CD4+ T cell regulation of CD25 expression controls development of short-lived effector CD8+ T cells in primary and secondary responses. Proc Natl Acad Sci U S A, 107(1), 193-198. doi:10.1073/pnas.0909945107

Ozga, A. J., Moalli, F., Abe, J., Swoger, J., Sharpe, J., Zehn, D., . . Stein, J. V. (2016). pMHC affinity controls duration of CD8+ T cell-DC interactions and imprints timing of effector differentiation versus expansion. J Exp Med, 213(12), 2811-2829. doi:10.1084/jem.20160206

Palmer, E. (2003). Negative selection - Clearing out the bad apples from the T-cell repertoire. Nature Reviews Immunology, 3(5), 383-391. doi:10.1038/nri1085

Parkhurst, M. R., Fitzgerald, E. B., Southwood, S., Sette, A., Rosenberg, S. A., \& Kawakami, Y. (1998). Identification of a shared HLA-A*0201 restricted T-cell epitope from the melanoma antigen tyrosinase-related protein 2 (TRP2). Cancer Research, 58(21), 48954901.

Pauken, K. E., Sammons, M. A., Odorizzi, P. M., Manne, S., Godec, J., Khan, O., ... Wherry, E. J. (2016). Epigenetic stability of exhausted T cells limits durability of reinvigoration by PD-1 blockade. Science, 354(6316), 1160-1165. doi:10.1126/science.aaf2807

Philip, M., Fairchild, L., Sun, L., Horste , E. L., Camara , S., Shakiba , M., ... Schietinger, A. (2017). Chromatin states define tumour-specific T cell dysfunction and reprogramming. Nature, 545, 452-456. doi:doi:10.1038/nature22367

Preston, G. C., Sinclair, L. V., Kaskar, A., Hukelmann, J. L., Navarro, M. N., Ferrero, I., . . . Cantrell, D. A. (2015). Single cell tuning of Myc expression by antigen receptor signal strength and interleukin-2 in T lymphocytes. EMBO J, 34(15), 2008-2024. doi:10.15252/embj.201490252

Redmond, W. L., \& Sherman, L. A. (2005). Peripheral tolerance of CD8 T lymphocytes. Immunity, 22(3), 275-284. doi:10.1016/j.immuni.2005.01.010

Richards, D. M., Kyewski, B., \& Feuerer, M. (2016). Re-examining the Nature and Function of Self-Reactive T cells. Trends in Immunology, 37(2), 114-125. doi:10.1016/j.it.2015.12.005

Richards, D. M., Ruggiero, E., Hofer, A. C., Sefrin, J. P., Schmidt, M., von Kalle, C., \& Feuerer, M. (2015). The Contained Self-Reactive Peripheral T Cell Repertoire: Size, Diversity, and Cellular Composition. Journal of Immunology, 195(5), 2067-2079. doi:10.4049/jimmunol.1500880

Rosenberg, S. A. (2014). IL-2: the first effective immunotherapy for human cancer. J Immunol, 192(12), 5451-5458. doi:10.4049/jimmunol.1490019 
945

946

947

948

949

950

951

952

953

954

955

956

957

958

959

960

961

962

963

964

965

966

967

968

969

970

971

972

973

974

975

976

977

978

979

980

981

982

983

Sabatino, J. J., Huang, J., Zhu, C., \& Evavold, B. D. (2011). High prevalence of low affinity peptide-MHC II tetramer-negative effectors during polyclonal CD4+ T cell responses. $J$ Exp Med, 208(1), 81-90. doi:10.1084/jem.20101574

Saligrama, N., Zhao, F., Sikora, M. J., Serratelli, W. S., Fernandes, R. A., Louis, D. M., . . Davis, M. M. (2019). Opposing T cell responses in experimental autoimmune encephalomyelitis. Nature, 572(7770), 481-487. doi:10.1038/s41586-019-1467-x

Schietinger, A., Delrow, J. J., Basom, R. S., Blattman, J. N., \& Greenberg, P. D. (2012). Rescued Tolerant CD8 T Cells Are Preprogrammed to Reestablish the Tolerant State. Science, 335(6069), 723-727. doi:10.1126/science.1214277

Schietinger, A., \& Greenberg, P. D. (2014). Tolerance and exhaustion: defining mechanisms of T cell dysfunction. Trends in Immunology, 35(2), 51-60. doi:10.1016/j.it.2013.10.001

Shiow, L. R., Rosen, D. B., Brdicková, N., Xu, Y., An, J., Lanier, L. L., . . Matloubian, M. (2006). CD69 acts downstream of interferon-alpha/beta to inhibit S1P1 and lymphocyte egress from lymphoid organs. Nature, 440(7083), 540-544. doi:10.1038/nature04606

Steitz, J., Brück, J., Lenz, J., Büchs, S., \& Tüting, T. (2005). Peripheral CD8+ T cell tolerance against melanocytic self-antigens in the skin is regulated in two steps by CD4+ T cells and local inflammation: implications for the pathophysiology of vitiligo. J Invest Dermatol, 124(1), 144-150. doi:10.1111/j.0022-202X.2004.23538.x

Stuart, T., Butler, A., Hoffman, P., Hafemeister, C., Papalexi, E., Mauck, W. M., .. Satija, R. (2019). Comprehensive Integration of Single-Cell Data. Cell, 177(7), 1888-1902.e1821. doi:10.1016/j.cell.2019.05.031

Su, L. F., Kidd, B. A., Han, A., Kotzin, J. J., \& Davis, M. M. (2013). Virus-specific CD4(+) memory-phenotype T cells are abundant in unexposed adults. Immunity, 38(2), 373-383. doi:10.1016/j.immuni.2012.10.021

Subramanian, A., Tamayo, P., Mootha, V. K., Mukherjee, S., Ebert, B. L., Gillette, M. A., . . Mesirov, J. P. (2005). Gene set enrichment analysis: a knowledge-based approach for interpreting genome-wide expression profiles. Proc Natl Acad Sci U S A, 102(43), 15545-15550. doi:10.1073/pnas.0506580102

Träger, U., Sierro, S., Djordjevic, G., Bouzo, B., Khandwala, S., Meloni, A., . . Simon, A. K. (2012). The immune response to melanoma is limited by thymic selection of selfantigens. PLoS One, 7(4), e35005. doi:10.1371/journal.pone.0035005

Valenzuela, J., Schmidt, C., \& Mescher, M. (2002). The roles of IL-12 in providing a third signal for clonal expansion of naive CD8 T cells. J Immunol, 169(12), 6842-6849.

Waithman, J., Gebhardt, T., Davey, G. M., Heath, W. R., \& Carbone, F. R. (2008). Cutting edge: Enhanced IL-2 signaling can convert self-specific $T$ cell response from tolerance to autoimmunity. J Immunol, 180(9), 5789-5793. doi:10.4049/jimmunol.180.9.5789

Wang, R. F., Appella, E., Kawakami, Y., Kang, X., \& Rosenberg, S. A. (1996). Identification of TRP-2 as a human tumor antigen recognized by cytotoxic T lymphocytes. J Exp Med, 184(6), 2207-2216. doi:10.1084/jem.184.6.2207 
Weninger, W., Crowley, M. A., Manjunath, N., \& von Andrian, U. H. (2001). Migratory properties of naive, effector, and memory CD8(+) T cells. J Exp Med, 194(7), 953-966.

986 Wickham, H. (2016). ggplot2: Elegant Graphics for Data Analysis. New York: Springer-Verlag.

987 Yu, W., Jiang, N., Ebert, P. J. R., Kidd, B. A., Muller, S., Lund, P. J., . . Davis, M. M. (2015). Clonal Deletion Prunes but Does Not Eliminate Self-Specific alpha beta CD8(+) T Lymphocytes. Immunity, 42(5), 929-941. doi:10.1016/j.immuni.2015.05.001

Zehn, D., \& Bevan, M. J. (2006). T cells with low avidity for a tissue-restricted antigen routinely evade central and peripheral tolerance and cause autoimmunity. Immunity, 25(2), 261-

Zehn, D., Lee, S. Y., \& Bevan, M. J. (2009). Complete but curtailed T-cell response to very lowaffinity antigen. Nature, 458(7235), 211-214. doi:10.1038/nature07657

Zhang, S., Bernard, D., Khan, W. I., Kaplan, M. H., Bramson, J. L., \& Wan, Y. (2009). CD4+ Tcell-mediated anti-tumor immunity can be uncoupled from autoimmunity via the STAT4/STAT6 signaling axis. Eur J Immunol, 39(5), 1252-1259.

999

1000

1001 doi:10.1002/eji.200839152

1002

Zheng, G. X., Terry, J. M., Belgrader, P., Ryvkin, P., Bent, Z. W., Wilson, R., . . Bielas, J. H. (2017). Massively parallel digital transcriptional profiling of single cells. Nat Commun, 8, 14049. doi:10.1038/ncomms 14049

1003 
bioRxiv preprint doi https://doi org/10.1101/2020.1216.423036; this version posted December 16, 2020. The copyright holder for this preprint

(which was not certified by peer review) is the author/funder, who has granted bioRxiv a license to display the preprint in perpetuity. It is made available under aCC-BY 4.0 International license.

\section{Non-standard abbreviations}

1005

$1006 D c t^{+-}$, dopamine tautomerase deficient

1007 DNFB, dinitrofluorobenzene

1008 LmTrp2, Listeria monocytogenes strain expressing Trp2

$1009 \mathrm{MFI}$, median fluorescence intensity

1010 Treg, regulatory $T$ cell

1011 Trp2, tyrosinase-related protein 2

1012 UMAP, uniform manifold approximation and projection

1013 


\section{Supplemental figures}

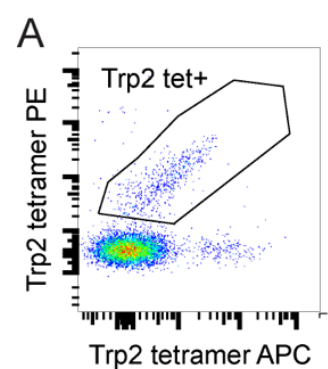

$\mathrm{D}$
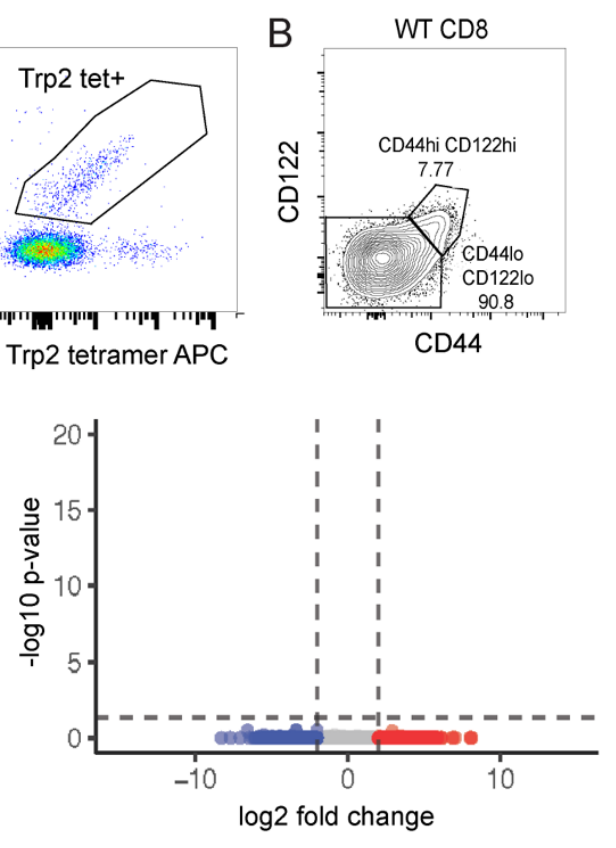
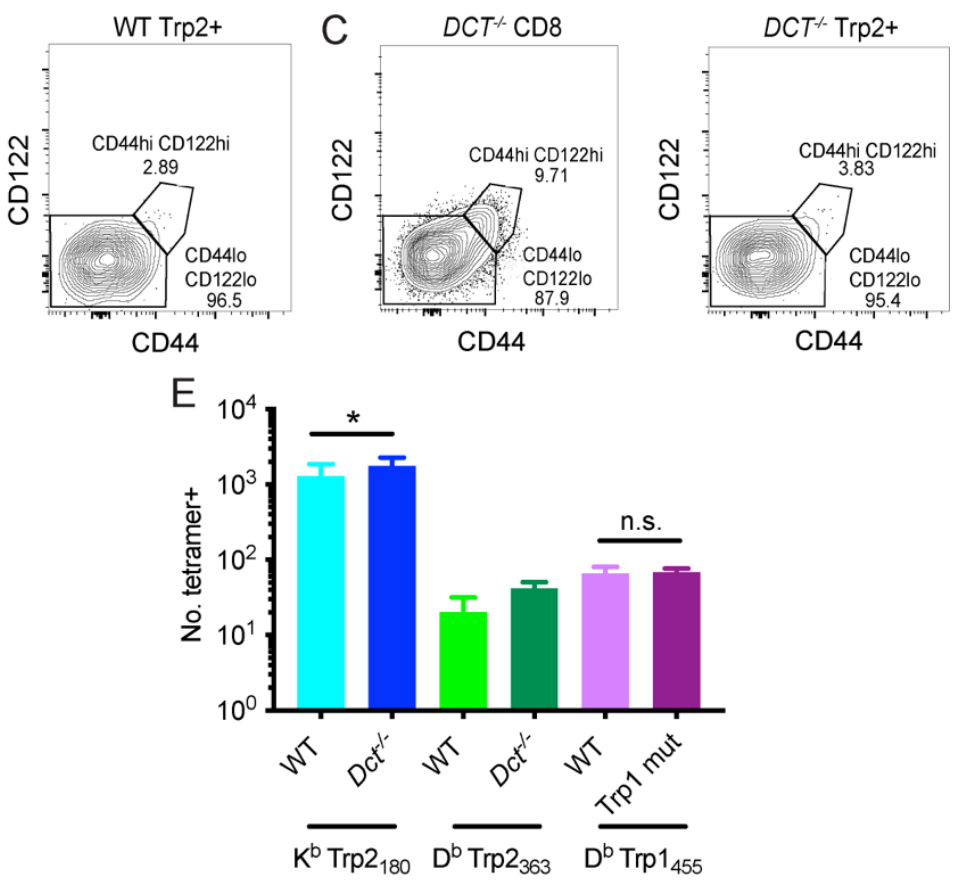

Supplemental figure 1. Additional analysis of the $\operatorname{Trp}^{2} / \mathrm{K}^{\mathrm{b}}$-specific population and cells specific for other melanocyte epitopes in pre-immune mice.

(A) Tetramer staining of pre-immune lymphocytes (enriched fraction, gated on live, dumpnegative CD8+ T cells). Dual tetramer staining was used to facilitate more accurate gating on antigen-specific cells. (B, C) CD44 and CD122 staining of pre-immune Trp2/K $\mathrm{K}^{\mathrm{b}}$-specific cells from a WT mouse (B) and a Dct ${ }^{--}$mouse (C). (D) Bulk RNA sequencing of Trp2/K ${ }^{\mathrm{b}}$-specific CD8+ T cells from pre-immune WT and $D c t^{\prime-}$ mice was performed; differentially expressed genes were not identified between WT and $D c t^{-}$samples as shown by the volcano plot. (E) Quantification of CD8+ T cells specific for a $D^{b}$-restricted Trp2 epitope and an epitope from tyrosinase-related protein 1 (Trp1) in pre-immune mice reveals a similar or slightly lesser number of cells in mice expressing antigen (WT mice) relative to those that do not. Samples used for tetramer enrichment of Trp1/ $D^{b}$-specific cells were obtained from shipped samples; accordingly, these data likely underestimate the precursor frequency. PC, principal component. ${ }^{*} p<.05$ by one-way ANOVA with Sidak's multiple comparisons test. 


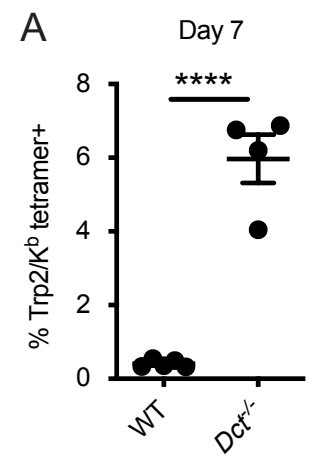

E WT transfer

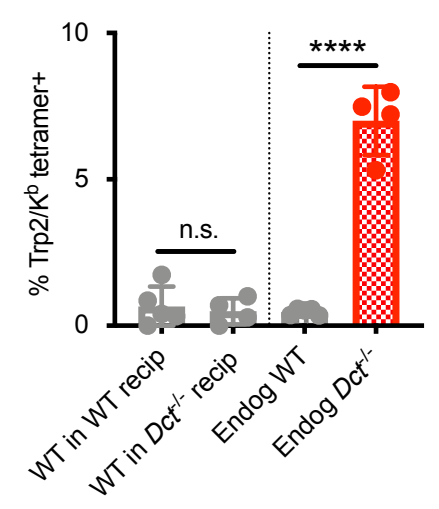

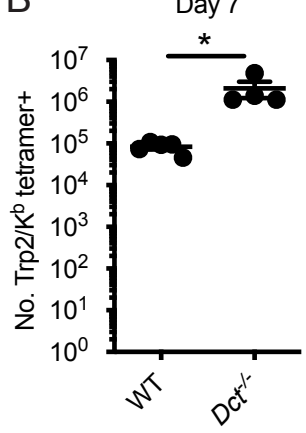

$\mathrm{F}$

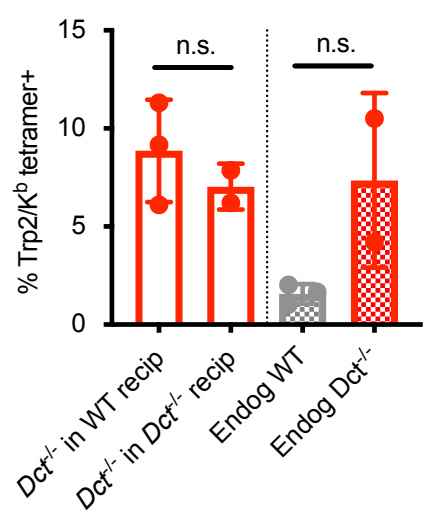

C

D Day 7 ex vivo peptide stimulation
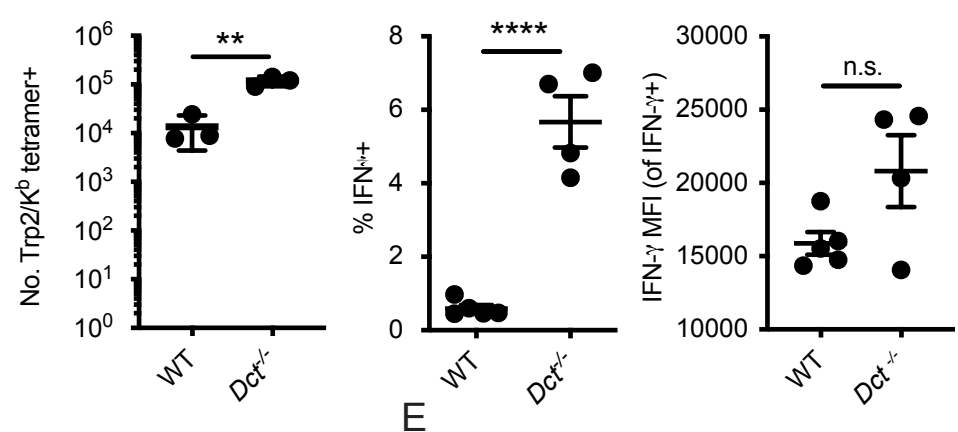

Supplemental figure 2. Response to infection with LmTrp2 in primary and transfer settings

Mice were infected with a recombinant Listeria monocytogenes strain expressing Trp2 (LmTrp2; A-D). The percent (A) or number (B, C) of splenic Trp2/Kb-specific cells was assessed at the indicated day. (D) Day 7 splenocytes were stimulated for 4-6 hours with Trp2 peptide and intracellular staining was performed to assess cytokine production. (E, F) CD8+ T cells from pre-immune WT or Dct- donors were negatively enriched and bulk CD8+ T cells were transferred into congenically distinct WT or Dct/- recipients. One day later, mice were infected with LmTrp2. Donor and endogenous cells were collected from the blood of recipient mice on day 7 following infection and assessed for $T r p 2 / K^{b}$ tetramer binding. Data in $A, B$, and $D$ are representative of 3 similar experiments; data in $C, E$, and $F$ represent individual experiments with 2-5 mice per group. Squares indicate male animals. ${ }^{*} p<0.05$, ${ }^{* *} p<0.01,{ }^{* * *} p<0.001$, ${ }^{* * * *} p<0.0001$ by unpaired t test (A-D) or one-way ANOVA with Sidak's multiple comparisons test (E, F). Endog, endogenous; recip, recipients. 
A

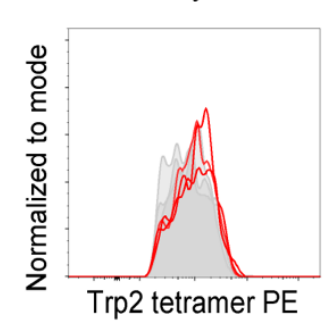

Day 3

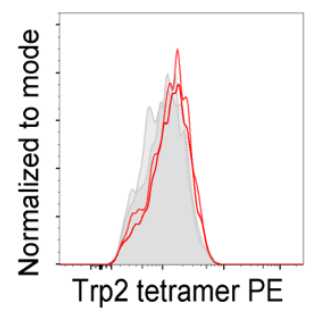

Day 4

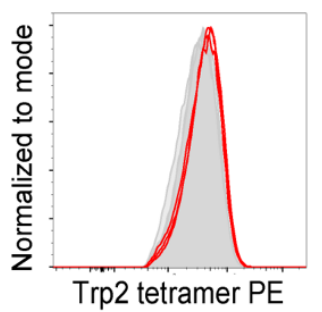

Day 7

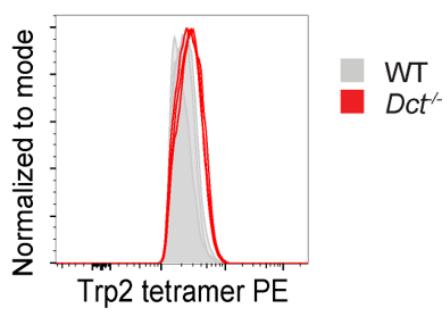

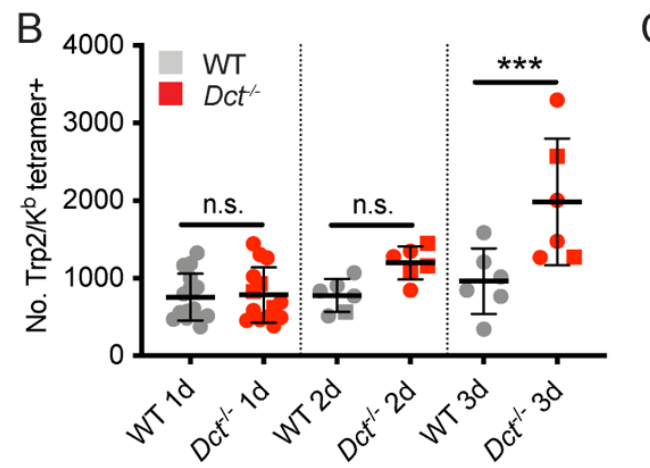

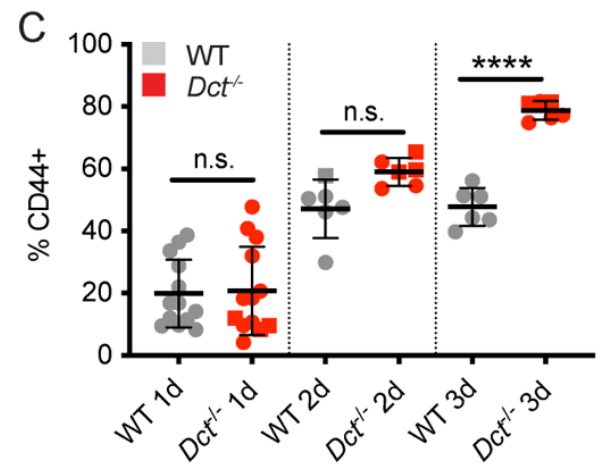

Supplemental figure 3. Tetramer staining kinetics and response to peptide immunization. WT and $D c t^{--}$mice received intravenous injections of $200 \mathrm{ug}$ Trp2 peptide as part of TriVax (A) or alone (B-D). (A) Histograms of tetramer staining for Trp2/Kb-binding cells. (B-D) Tetramer enrichment was used to enumerate Trp2/ $\mathrm{K}^{\mathrm{b}}$-specific cells and assess their phenotype at the indicated time points following peptide injection; males are indicated by square symbols. Data from representative experiments at each time point are shown in (A). Data in B-D are compiled from multiple experiments. ${ }^{* * *} p<0.001,{ }^{* * * *} p<0.0001$ by one-way ANOVA with Sidak's multiple comparisons test. 
bioRxiv preprint doi: https://doi.org/10.1101/2020.12.16.423036; this version posted December 16,2020 . The copyright holder for this preprint (which was not certified by peer review) is the author/funder, who has granted bioRxiv a license to display the preprint in perpetuity. It is made available under aCC-BY 4.0 International license.

A
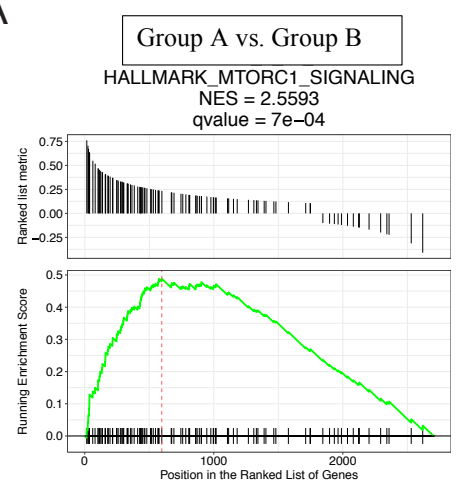

HALLMARK_MYC_TARGETS_V1 $\begin{aligned} \mathrm{NES} & =3.2297 \\ \text { qvalue } & =7 \mathrm{e}-04\end{aligned}$

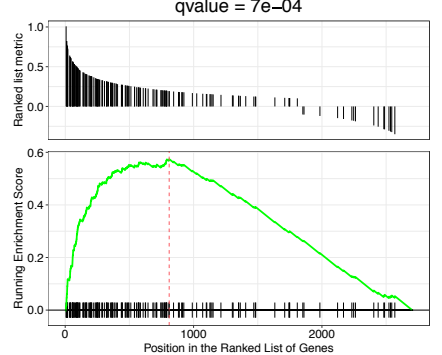
$\begin{array}{rl}1000 & 2000 \\ \text { Position in the Ranked List of Genes } & \end{array}$
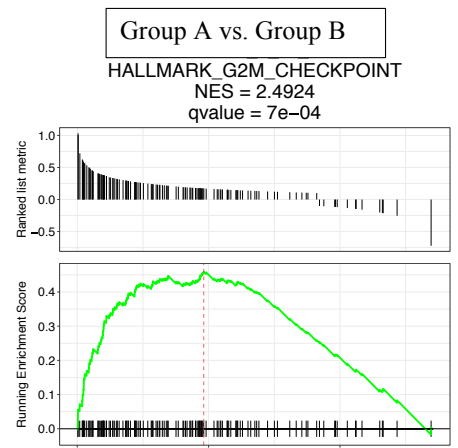
2000
Position in the Ranked List of Genes

HALLMARK_E2F_TARGETS $\mathrm{NES}=2.8823$

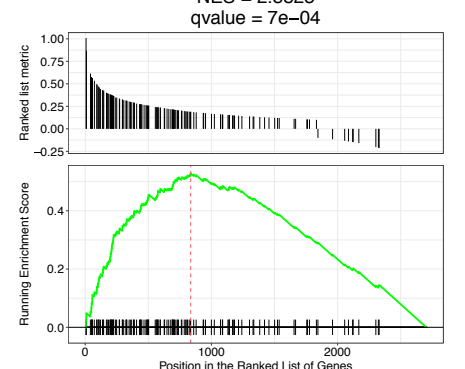

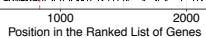

B Fung_IL2 signaling_1

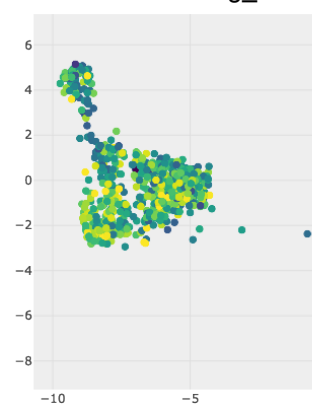

C

TriVax

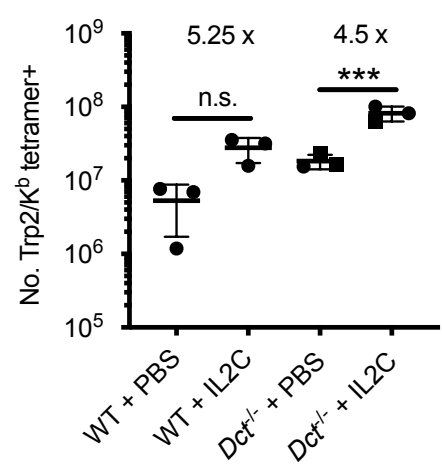

Supplemental figure 4. GSEA of single-cell data and response of WT and $D c t^{-1-}$ Trp2/Kb-specific cells to IL-2C (A) Gene set enrichment analysis (GSEA) plots show enrichment of the following gene sets in Group A: Myc targets, MTORC1 signaling, G2M checkpoint, E2F targets. (B) Enrichment between clusters and a dataset of genes involved in IL-2 signaling is indicated by color. (C, D) WT and Dct ${ }^{\text {- }}$ mice were immunized with TriVax (C) or infected with LmTrp2 (D) and treated with PBS or IL-2C on day five. Trp2 $/ \mathrm{K}^{\mathrm{b}}$ tetramer positive splenocytes were enumerated on day seven after priming/infection. Squares indicate male animals. ${ }^{*} p<$ $0.05,{ }^{* * * *} p<0.0001$ by one-way ANOVA with Tukey's multiple comparisons test. IL-2C, IL-2 complex. 
bioRxiv preprint doi: https://doi.org/10.1101/2020.12.16.423036; this version posted December 16, 2020. The copyright holder for this preprint (which was not certified by peer review) is the author/funder, who has granted bioRxiv a license to display the preprint in perpetuity. It is made available under aCC-BY 4.0 International license.

A

Vitiligo scoring metric
\begin{tabular}{|c|l|}
\hline Score & Description \\
\hline 0 & No vitiligo \\
\hline 1 & Possible vitiligo \\
\hline 2 & Definite but limited vitiligo: some hair or a small tuft \\
\hline 3 & Small patch of vitiligo \\
\hline 4 & Large patch of vitiligo $\left(>1 \mathrm{~cm}^{2}\right)$ or multiple small patches \\
\hline 5 & $\begin{array}{l}\text { Extensive vitiligo (multiple large patches, } \\
\text { patch + many hairs, etc.) }\end{array}$ \\
\hline
\end{tabular}

B

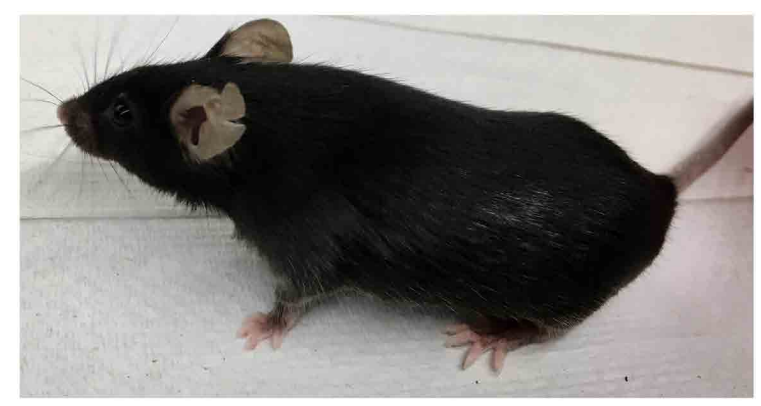

Example of a grade 2 mouse (received WT cells)
D

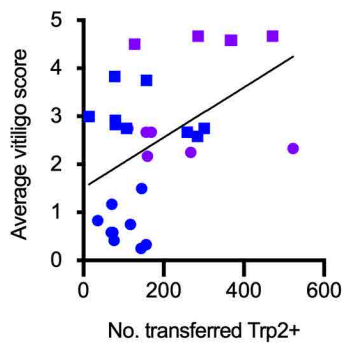

$\mathrm{R}^{2}=0.23$

$p=0.0089$

Colors indicate

different experiments

Circles $=\mathrm{WT}$, squares $=\mathrm{KO}$

C

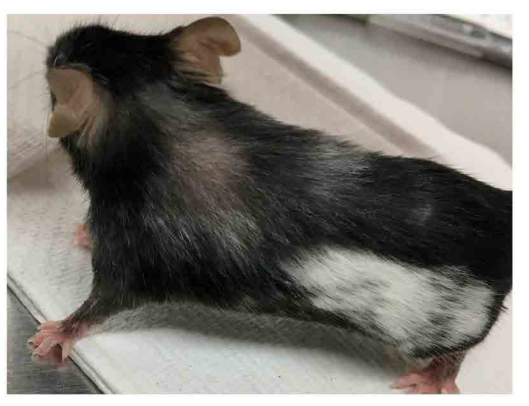

Example of a grade 5 mouse (received Dct ${ }^{-}$cells)

Supplemental figure 5 . Vitiligo scoring metric and correlation between the average vitiligo score and the number of transferred Trp2/K $\mathrm{K}^{\mathrm{b}}$-specific cells

(A) Vitiligo scoring metric used to quantify the degree of vitiligo. (B) Example of a grade 2 mouse; (C) example of a grade 5 mouse. (D) Average vitiligo score per mouse (days 0-93) relative to the number of transferred Trp2 $/ \mathrm{K}^{\mathrm{b}}$ tetramer positive cells on day six after transfer and TriVax boost. Two compiled experiments are shown. Simple linear regression was used to fit a line and assign $\mathrm{R}^{2}$ and $\mathrm{p}$-values. 